\title{
Contributions of Family Leisure to Family Functioning Among Single-Parent Families
}

Laurel Beth Hornberger

Brigham Young University - Provo

Follow this and additional works at: https://scholarsarchive.byu.edu/etd

Part of the Recreation Business Commons

\section{BYU ScholarsArchive Citation}

Hornberger, Laurel Beth, "Contributions of Family Leisure to Family Functioning Among Single-Parent Families" (2007). Theses and Dissertations. 1172.

https://scholarsarchive.byu.edu/etd/1172

This Thesis is brought to you for free and open access by BYU ScholarsArchive. It has been accepted for inclusion in Theses and Dissertations by an authorized administrator of BYU ScholarsArchive. For more information, please contact scholarsarchive@byu.edu, ellen_amatangelo@byu.edu. 
CONTRIBUTIONS OF FAMILY LEISURE TO FAMILY FUNCTIONING

AMONG SINGLE-PARENT FAMILIES

by

Laurel B. Hornberger

A thesis submitted to the faculty of

Brigham Young University

in partial fulfillment of the requirements for the degree of

Master of Science

Department of Recreation Management and Youth Leadership

Brigham Young University

August 2007 
BRIGHAM YOUNG UNIVERSITY

GRADUATE COMMITTEE APPROVAL

of a thesis submitted by

Laurel B. Hornberger

This thesis has been read by each member of the following graduate committee and by majority vote has been found to be satisfactory.

Date

Date

Date
Ramon B. Zabriskie, Chair

Patti A. Freeman

Dennis L. Eggett 


\section{BRIGHAM YOUNG UNIVERSITY}

As chair of the candidate's graduate committee, I have read the thesis of Laurel B. Hornberger in its final form and have found that (1) its format, citations, and bibliographical style are consistent and acceptable and fulfill university and department style requirements; (2) its illustrative materials including figures, tables, and charts are in place; and (3) the final manuscript is satisfactory to the graduate committee and is ready for submission to the university library.

Date

Accepted for the Department
Ramon B. Zabriskie

Chair, Graduate Committee
Patti A. Freeman

Chair, Department of Recreation Management and Youth Leadership

Accepted for the College

Gordon B. Lindsay, Associate Dean

College of Health and Human Performance 


\title{
ABSTRACT \\ CONTRIBUTIONS OF FAMILY LEISURE TO FAMILY FUNCTIONING AMONG SINGLE-PARENT FAMILIES
}

\author{
Laurel B. Hornberger \\ Department of Recreation Management and Youth Leadership \\ Master of Science
}

The purpose of this study was to examine the contribution of family leisure involvement to the family functioning of single-parent families among a large national representative sample. Two samples were gathered. The single-parent sample consisted of 384 families (384 parents and 384 youth). The dual-parent sample consisted of 495 families (495 parents and 495 youth). Data were analyzed from the parent, youth, and family perspective using two instruments. The Family Adaptability and Cohesion Scale (FACES II) was used to measure family functioning and the Family Leisure Activity Profile (FLAP) was used to measure family leisure involvement. Blocked multiple regression analysis indicated a positive relationship between family leisure variables and family functioning variables among single-parent families. Family cohesion and family adaptability were affected by both core and balance activities, while family adaptability was affected slightly more by core activities than balance activities, from all three perspectives. Results also indicated that family functioning was very similar to dual- 
parent families while family leisure involvement among single-parent families was less. Implications for practitioners and recommendations for further research are discussed. 


\section{ACKNOWLEDGMENTS}

I would like to thank all those whose invaluable support aided in the completion of this thesis. First I would like to thank Ramon Zabriskie for his enthusiasm and encouragement and many hours he put towards this; Patti Freeman for her insights and time; and Dennis Eggett for his time and support in the analysis. I would like to thank Kevin Smith for his help with the Web. I would like to extend my gratitude and appreciation to all those in the Division of Continuing Education at BYU, especially to Rob Holcombe and Steve Taggart, who have encouraged and supported me throughout, allowing me to continue my schooling while working. I would also like to thank my dear friends (Debbie, Kellie, Lizzy, Melinda, \& Poliana) for their tireless encouragement, understanding, and strength they extended to me. I would especially like to thank all my family for their support and understanding, my parents for their inspiration, Kathaleen and Heidi for their time in editing and invaluable insights, and especially Dorthy, for her perseverance and encouragement throughout this whole pursuit and whom I could never have started or finished this goal without. The day we walk TOGETHER (like we have since we were little) at graduation will be a day I will always remember. Thank you! Finally, I owe my all to my Heavenly Father and Savior Jesus Christ, forever. 
List of Tables viii

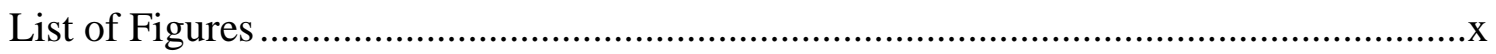

Contributions of Family Leisure to Family Functioning Among Single-Parent Families

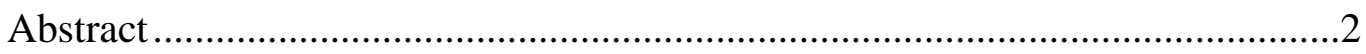

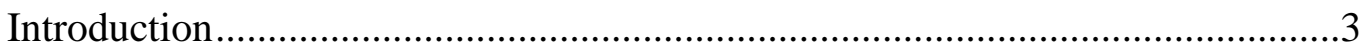

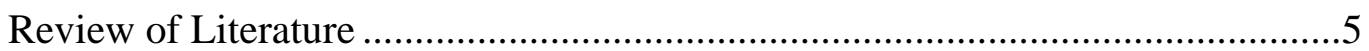

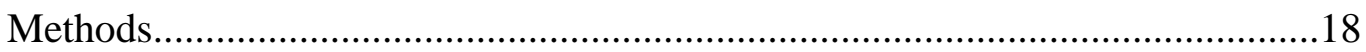

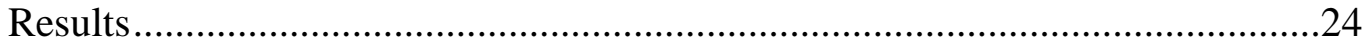

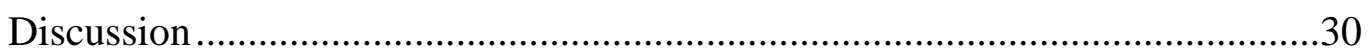

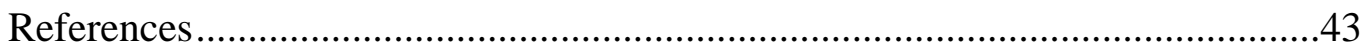

Appendix A Prospectus..............................................................................64

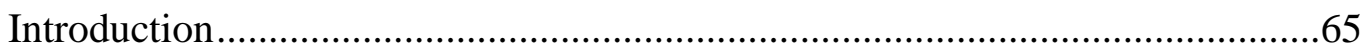

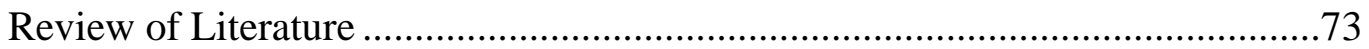

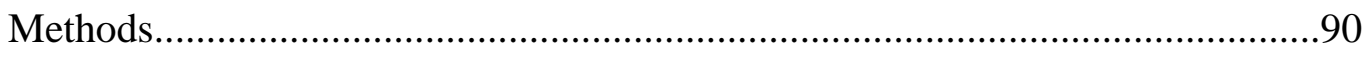

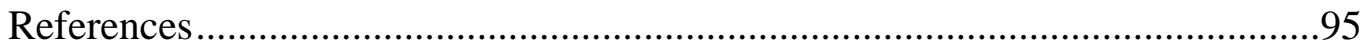

Appendix A-1a Informed Consent ............................................................101

Appendix A-1b Family Leisure Activity Profile .............................................104

Appendix A-1c Family Adaptability and Cohesion Scale II ...........................118

Appendix A-1d Demographic Questions....................................................120 


\section{List of Tables}

Table

Page

1 Differences Between Single-Parent Families and Dual-Parent Families on Cohesion, Adaptability, and Family Functioning

2 Differences Between Single-Parent Families and Dual-Parent Families on Family Leisure Patterns ....................................................................... 50

3 Zero Order Pearson Correlations: Parent Data ........................................... 51

4 Zero Order Pearson Correlations: Youth Data............................................... 52

5 Zero Order Pearson Correlations: Family Data (Parent \& Youth) .................. 53

6 Summary of Blocked Regression Equations Predicting Family

Cohesion: Parent Data..................................................................................... 54

7 Summary of Blocked Regression Equations Predicting Family

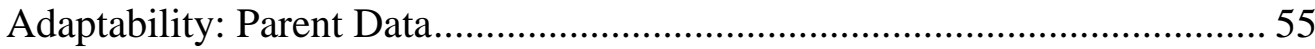

8 Summary of Blocked Regression Equations Predicting Family

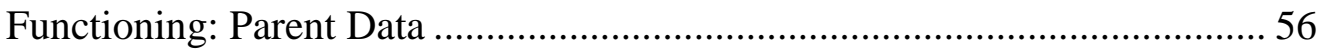

9 Summary of Blocked Regression Equations Predicting Family

Cohesion: Youth Data.................................................................................... 57

10 Summary of Blocked Regression Equations Predicting Family

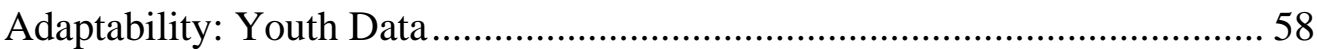

11 Summary of Blocked Regression Equations Predicting Family

Functioning: Youth Data..... 59

12 Summary of Blocked Regression Equations Predicting Family Cohesion: Family Data (Parent \& Youth) 60 
13 Summary of Blocked Regression Equations Predicting Family

Adaptability: Family Data (Parent \& Youth)....................................................... 61

14 Summary of Blocked Regression Equations Predicting Family

Functioning: Family Data (Parent \& Youth)

62 


\section{List of Figures}

Figure Page

1 Core and Balance Model of Family Leisure Functioning.............................63 
Running head: FAMILY LEISURE IN SINGLE-PARENT FAMILIES

Contributions of Family Leisure to Family Functioning

Among Single-Parent Families

Laurel B. Hornberger, M.S.

Brigham Young University 
2 Family Leisure in Single-Parent Families

\begin{abstract}
The primary purpose of this study was to examine the contribution of family leisure involvement to the family functioning of single-parent families among a large national representative sample. The secondary purpose was to compare family functioning and family leisure involvement between large national samples of dual-parent and single-parent families. Two samples were gathered. The single-parent sample consisted of 384 families (384 parents and 384 youth) and the dual-parent sample consisted of 495 families (495 parents and 495 youth). Data were analyzed from the parent, youth, and family perspective using two instruments. The Family Adaptability and Cohesion Scale (FACES II) was used to measure family functioning and the Family Leisure Activity Profile (FLAP) was used to measure family leisure involvement. Blocked multiple regression analysis indicated a positive relationship between family leisure variables and family functioning variables among single-parent families. Family cohesion and family adaptability were related to both core and balance family leisure involvement, with core family leisure involvement explaining more variance in family functioning variables from all three perspectives. Results also indicated that family functioning was very similar to dual-parent families while family leisure involvement among single-parent families was less. Implications for practitioners and recommendations for further research are discussed.
\end{abstract}

Key words: balance leisure patterns, core leisure patterns, family adaptability, family cohesion, family functioning, family leisure patterns, dual-parent family, single-parent family. 


\section{Contributions of Family Leisure to Family Functioning}

\section{Among Single-Parent Families}

A variety of "severe and complex difficulties" often accompany single-parent families and their "tenuous status in society" (Greif, 1996, p. 19). These difficulties are dependant on their family structure, whether they are headed by a father or a mother, and whether the single-parent status is a result of the parent nevermarrying, divorce, death, or military service (Greif). Society is experiencing a significant increase in the number of single-parent families, and this growth is predicted to continue in years to come (Garanzini, 1995). The family is the basic unit of society, and with the number of singleparent families growing significantly (Garanzini) it is important to gain an understanding regarding what may influence family functioning among them.

Family functioning is described by Olsen (1993) as a delicate balance between family cohesion or closeness and family adaptability or the capacity to be flexible and adapt to challenges and changes both within the family and within their environment. Family leisure involvement has been identified as one of the many variables related to healthy family functioning.

Over the past decades, the study of family leisure has evolved with a consistent positive relationship found between quality time spent together in leisure pursuits as a family (Hawks, 1991). Zabriskie and McCormick (2001) correlated family leisure and the family systems theory, which suggested that cohesion, adaptability, and communication from Olson's (1986) Circumplex Model, were directly facilitated through involvement in family leisure. This instigated the development of a new model used to study the 
4 Family Leisure in Single-Parent Families

relationship between family leisure and family functioning. The Core and Balance Model of Family Leisure Functioning (Zabriskie, 2000) is grounded in the family systems theory and "suggests that there is a direct relationship between" family leisure patterns and family cohesion and adaptability (Zabriskie \& Freeman, 2004, p. 54).

The Core and Balance Model of Family Leisure Functioning is used as a framework in several studies that have reported significant correlations between family leisure involvement and family functioning among traditional families, whether examined from a parent, child, or family perspective (Freeman \& Zabriskie, 2003; Zabriskie, 2000, 2001; Zabriskie \& Freeman, 2004; Zabriskie \& McCormick, 2001, 2003). Researchers have used the same framework and reported similar results among samples with different family structures such as families with a child with a disability (Dodd, 2007), families with special needs adoptive children (Zabriskie \& Freeman), families with youth in mental health treatment, and Hispanic families (Christenson, Zabriskie, Eggett, \& Freeman, 2006). There is very little research, however, regarding the contribution of family leisure involvement to family functioning among single-parent families.

The limited literature suggests there may be a strong relationship between family leisure and family functioning among single-parent families (Smith, Taylor, Hill, \& Zabriskie, 2004). A recent pilot study reported "a relatively strong relationship between family leisure involvement and family functioning among those in a single-parent family structure" (Smith et al., p. 53). Findings also indicate that when compared to dual-parent families, single-parent families reported lower family functioning and less family leisure involvement. This study had several limitations which resulted in the authors 
recommending that data be gathered from a broad, more representative sample of singleparent families, and from multiple perspectives of those living in the home. Given the limited research on single-parent families and the relationship between family functioning and family leisure involvement, it is imperative to better understand family leisure functioning among singe-parent families. Therefore, the primary purpose of this study was to examine the contribution of family leisure involvement to the family functioning of single-parent families among a large national representative sample. The secondary purpose was to compare family functioning and family leisure involvement between large national samples of dual-parent and single-parent families

\section{Review of Literature}

\section{Family Functioning}

Family systems theory is one of the most widely accepted and utilized paradigms for understanding families and family behaviors (Broderick, 1993). This framework suggests that the family unit is greater than the sum of its parts; therefore, viewing the family as a whole is most representative of the family when seeking to understand the family's behavior. Many models have been created to describe the family systems framework, but Olson's (1993) Circumplex Model of Marital and Family Systems is used most often. This model was built to bridge the gap often present between research, theory, and practice. It focuses on a relations system and "integrates three dimensions that have repeatedly been considered highly relevant in a variety of family theory models and family therapy approaches, namely, family cohesion, [adaptability], and communication" (Olson, 1993, p. 515). Communication is considered a facilitating 


\section{Family Leisure in Single-Parent Families}

dimension and thus is not included graphically in the model with cohesion and adaptability; therefore the focus will remain on the latter two.

Olson (1993) defined family cohesion "as the emotional bonding that couples and family members have toward one another" (p. 516). The level of cohesion was determined by the family system's balance of separateness and togetherness. Olson (1993) defined family adaptability as "the amount of change in its leadership, role relationships, and relationship rules. [Adaptability] concerns how systems balance stability with change" (p. 519). Stability and change were a necessity of couples and families, and the ability to change when the need arose was a defining characteristic of functional couples and families. There are many different family types and each type has optimal levels of family functioning. Single-parent families are one of the many different family types that must deal with many unique issues that affect their family functioning.

\section{Single-Parent Families}

The United States was experiencing a significant increase in the number of singleparent families, and this growth was predicted to continue in years to come. Single-parent families headed by mothers increased to 10 million in the year 2000, from 3 million in 1970. Single-parent families headed by fathers increased to 2 million from 393,000 in those same years (Family Discipleship Ministries, 2002). In 1950, nearly $80 \%$ of the children born were expected to be reared in their early years by two parents (Garanzini, 1995). Conversely, in 1995 almost $50 \%$ of the children born were expected to spend at least some of their early years in a single-parent family (Garanzini). In 1986 about 88\% 
of single-parent families were headed by mothers and $12 \%$ by fathers. About $7 \%$ of single-parent families were single as a result of the death of a parent, while the majority were single as a result of divorce. Nearly one in four children (24\%) were living with their mother who never married (Garfinkle \& McLanahan, 1986). These different types of single-parent families have different types of challenges they must deal with.

Many difficulties accompany these families and are dependant on their family structure, whether they are headed by a father or a mother, and whether the single-parent status is a result of the parent nevermarrying, divorce, death, or military service. Singleparent families have many severe and complex challenges which accompany their weak status in society (Greif, 1996).

Single mothers face financial difficulties resulting from the dual role they must fill to care and provide for their children; their meager child support, if they receive such; and their usually low income (Garfinkle \& McLanahan, 1986). In the United States, the poverty rate of female-headed households is six times greater than that of other families (U.S. Bureau of the Census, 1992). On the other hand, single fathers are usually better educated and are more likely to have stable, higher paying jobs, thus enabling them to maintain a higher standard of living (Garanzini, 1995; Hoffman \& Duncan, 1988). When comparing single-parent families headed by fathers and mothers, Garanzini stated, "fathers are able to gain compliance from their children more than are single mothers," but they feel more insecure than mothers about caring for their children's emotional needs (Garanzini, p. 95). There are also a variety of struggles that accompany each single-parent family, depending on the reason they are a single-parent family. 
8 Family Leisure in Single-Parent Families

When the death of a spouse occurs, the children are given the necessary permission to grieve the loss of their parent, no matter the length of time required. This is not usually the case when the status of a single-parent family results from a divorce. The knowledge of the separation and divorce is usually kept private. With the complications of divorce, it is potentially more stressful on the parent and children than the death of a spouse/parent (Garanzini,1995). The resulting pressures and struggles that fall upon single-parent families, regardless of the cause of their "singlehood," whether it be through death, divorce, or other means, can cause immense stress on them and their successful family functioning (Garanzini).

Single-parent families are more than twice as likely to have stressful family environments than dual-parent families (Moore \& Vandivere, 2000). Such stresses include poor health and inability to meet essential household expenses, such as food, shelter, and adequate health care. One in five children in the United States living in stressful family environments are likely to exhibit high levels of emotional and behavioral problems by almost four times as much, and are almost two times more likely to under perform in school than those children living in nonstressful family environments (Moore \& Vandivere).

The parent-child relationship can often be under duress in single-parent families, resulting in unhealthy adaptations. Depression and low self-esteem are common feelings single parents must deal with, and these feelings have a negative effect on their 
relationship with family functioning and family processes (Brody \& Flor, 1997;

Garanzini, 1995). This may then cause the child to act out, seeking attention for his or her unmet developmental needs (Garanzini; Wallerstein, Lewis, \& Blakeslee, 2000).

Some problems for single-parents Cooney and Mortimer (1999) address are household chores and a lack of parental supervision in single-parent families. Often twice as much help is required from the children of single-parent families than those of dualparent families (Cooney \& Mortimer), which can be a great source of contention. Also single parents are believed to monitor their teenagers' activities less closely than dualparents, which results in "undesirable, age-inappropriate behaviors" (p. 373) of the teenagers. This lack of parental monitoring is believed to create a deep peer orientation in teenagers, much more so than in those teenagers who are monitored closely by their parents. Single-parents have reported that their children became more difficult to manage over time due to adolescence (Richards \& Schmiege, 1993). Parents mention such struggles as their teenagers using illegal substances and having early contact with police (McLanahan \& Sandefur, 1994).

Another common problem in single-parent families occurs when the parent uses his or her child as a substitute for the missing spouse. This forces the child into an unnatural adult role, that of emotionally caring for the parent, and becoming the parent's confidant (Garanzini, 1995; Greif, 1996). Often these issues can result in negative family functioning in single-parent families. Many studies have focused on variables related to positive family functioning, and family leisure involvement has consistently indicated such a relationship. 
10 Family Leisure in Single-Parent Families

Several studies have reported a positive relationship of family leisure involvement on family functioning among families with different family structures, including specialneeds adoptive families and families with a child who has a disability (Freeman \& Zabriskie, 2003; Mactavish, \& Schleien, 1998; Mactavish, \& Schleien, 2004; Scholl, McAvoy, Rynders, \& Smith, 2003). Little is known, however, about family leisure among single-parent families. Recent studies suggested that there may be a strong relationship between family leisure and family functioning among single-parent families. (Smith, et al., 2004; Taylor, et al., 2004).

\section{Family Leisure}

The study of family leisure has evolved over the past 70 years with a consistent positive relationship found between successful family functioning and family leisure (Hawks, 1991). In the last decade, several researchers have examined different aspects of family functioning in regards to family leisure and have continually found a positive relationship. Mactavish and Schleien (1998) found the benefits of the family leisure involvement to be skill building in certain adaptive areas such as negotiating, compromising, and problem solving. Zabriskie (2000) found a positive relationship between family leisure involvement and family functioning when measured from the perspectives of a child, a parent, and the family. Similarly, Scholl, et al., (2003) found an increase in family cohesion and satisfaction among families who have a child with a disability when participating in outdoor recreation as a family. In addition, Huff, Widmer, McCoy, and Hill (2003) found a reduction in conflict among families who participated in challenging outdoor recreation, due to an increased willingness to work together through 
Family Leisure in Single-Parent Families 11

disagreements and problems. Likewise, Wells, Widmer, and McCoy (2004) found an increase in family efficacy among families who participated in challenging activities. Although a positive relationship has been well established between family functioning and family leisure involvement, there have been several criticisms of the early body of research addressing the relationship between family leisure involvement and family functioning.

Freeman and Zabriskie (2003) stated, "the nature of the relationship [between family leisure and aspects of family functioning] is still poorly understood" (p. 75). Zabriskie and McCormick (2001) discussed some weaknesses in early research of family leisure which, when addressed, may help clarify the positive relationship between family leisure and family functioning. A majority of early family leisure research examined the relationship among married couples only, and inferred findings to the broader family system. Another concern in family leisure research involved leisure being typically “operationalized in a simplistic and inconsistent manner. Measurement has included any time spent together, as well as lists of activities placed into categories with no theoretical basis" (p. 283). This historical lack of an adequate theoretic framework has limited findings to the "idiosyncrasies of the investigation at hand" (Orthner \& Mancini, 1991, p. 299). Many scholars recognized this concern and called for theory based family leisure research (Hawks, 1991; Holman, \& Epperson, 1989; Orthner \& Mancini, 1990).

The need for a theoretic framework from which to examine family leisure may have been addressed in part by the family systems theoretical perspective, which offers a sound avenue from which to examine the relationship of family and leisure (Orthner \& 
12 Family Leisure in Single-Parent Families

Mancini, 1991). Family leisure and the family systems theory were correlated by Zabriskie and McCormick (2001). They suggested that family leisure would directly facilitate the three dimensions (cohesion, adaptability, and communication) of Olson's (1986) Circumplex Model. This instigated the development of a new model, the Core and Balance Model of Family Leisure Functioning (Zabriskie, 2000), used to study the relationship between family leisure and family functioning. It is grounded in the family systems theory and "suggests that there is a direct relationship between" family leisure patterns and family cohesion and adaptability (Zabriskie \& Freeman, 2004, p. 54).

Core and Balance Model of Family Leisure Functioning. To come to an understanding of the meaning and purpose of leisure for the individual, Kelly (1996, 1999) identified two main types of leisure that most people engage in throughout their life. One type is ongoing, stable, and easily accessible throughout one's life, while the second is opposite in nature. The second type of leisure adds variety, is less accessible and persistent, and is often changing throughout the course of one's life. Iso-Ahola (1984) indicated that individual behavior is influenced by the human need to create a balance between two opposing forces. He stated that individuals have a tendency to "seek both stability and change, structure and variety, and familiarity and novelty in [their] leisure" (p. 98). By participating in leisure activities of security (stability) and novelty (change), individuals fulfill the need for balancing stability and change.

Zabriskie and Freeman (2004) suggest that "this interplay between stability and change plays an even greater role when examining the needs of a family system" (p. 54). In family systems theory, the underlying concept "suggests that families seek a dynamic 
state of homeostasis. Families as a system have a need for stability in interactions, structure, and relationships, as well as a need for novelty in experience, input, and challenge" (Zabriskie \& McCormick, 2001, p. 283). Families, similar to individuals, seek such a balance through their leisure activities. This phenomenon is explained through the Core and Balance Model of Family Leisure Functioning (see Figure 1) (Zabriskie \& McCormick, 2001).

Zabriskie and McCormick's (2001) Core and Balance Model of Family Leisure Functioning divides the leisure patterns families use to achieve stability and change as they seek their dynamic state of homeostasis into two main categories (core and balance). Core family leisure patterns answer the need "for familiarity and stability" by providing regular family leisure experiences that are predictable in nature and help promote closeness among family members and personal relatedness (p. 283). Balance family leisure patterns, on the other hand, provide avenues for the family to be challenged, and to grow and develop as a functioning unit. In order for the family to have both stability (cohesion) and change (adaptability) it needs both core and balance activities in relatively equal amounts (p. 283).

Zabriskie and McCormick (2001) described core family leisure patterns as activities that cost little, may be participated in on a daily basis, are at home, and are ordinary activities that family members engage in often. These activities may include playing games, cooking, playing basketball or soccer at home, or simply playing in the yard. These activities provide an environment where family members can build and deepen relationships in the nonthreatening, familiar "at-home" feeling. Involvement in 


\section{Family Leisure in Single-Parent Families}

these activities provides a release from work and is consoling, rewarding, refreshing, and rejuvenating to those who participate in them. In addition they may provide a trial arena for the exploration of family boundaries, roles, and rules, where no one is hurt. Core leisure patterns are engaged in a socializing context which provides a means for communication, not only of the common everyday events, but also a more comfortable setting for expressing feelings and emotions of individuals. This results in interpersonal connectivity of family members which in turn builds family closeness and cohesion (Zabriskie \& McCormick, 2001).

Zabriskie and McCormick (2001) described balance patterns as activities that are less regular, participated in less often, and thus provide unique experiences. More time, effort, and money are often required for these activities and they usually take place away from home. Some examples of balance activities include traveling, vacations, outdoor activities, such as campouts, waterskiing, or fishing together as a family. Other balance activities may include miniature golf, attending sports events, or going to fairs or parks. Much planning often goes into balance activities and as a result, they are less spontaneous and occur less often and, they tend to last longer than core activities. These activities are usually accompanied with novelty and unpredictability, thus creating an environment of new input, challenges, and experiences family members must adapt to and negotiate with, including each other. These activities expose family members to unfamiliar and surprising stimuli from the environment, requiring them to learn and progress as a family unit (Zabriskie \& McCormick, 2001). 
Family Leisure in Single-Parent Families 15

An empirical and positive relationship between family leisure patterns and successful family functioning, involving family cohesion and adaptability, has been reported in several studies using the Core and Balance framework (Freeman \& Zabriskie, 2003; Zabriskie, 2000, 2001; Zabriskie \& Freeman, 2004; Zabriskie \& McCormick, 2001, 2003). Some of these studies have examined traditional families and have collected data from a young adult perspective, as well as a child, parent, and family perspective (Zabriskie, 2000; Zabriskie \& McCormick, 2001, 2003). There has also been a variety of known-group studies that have utilized the Core and Balance framework to examine different types of families with known characteristics. Some of these include families with special needs adoptive children (Zabriskie \& Freeman), families with youth in mental health treatment, and Hispanic families (Christenson et. al., 2006). Each knowngroup study has provided further support for the Core and Balance Model and its use for examining family leisure. More specifically it was found that core family leisure activities are related primarily to family cohesion while balance family leisure patterns are related primarily to family adaptability (Zabriskie \& Freeman; Zabriskie \& McCormick, 2001). Both core and balance family leisure patterns have been related to family functioning from parent, youth, and family perspectives (Freeman \& Zabriskie; Zabriskie \& Freeman; Zabriskie \& McCormick, 2003).

Zabriskie and McCormick (2001) suggested that participating in family leisure is quite possibly one of the rare experiences in which families today spend a large amount of time together, aside from a family crisis. Researchers have consistently found a positive correlation between successful family functioning and family leisure patterns. 
16 Family Leisure in Single-Parent Families

Zabriskie and Freeman (2004) found that "when considering other family characteristics such as race, family size, religion, history of divorce, and annual family income, the only significant predictor of higher family functioning was family leisure involvement" (p. 70). This body of research supported the claim that in today's society family leisure is one of the most important elements in building cohesive relationships in families (Couchmanm 1988, as cited in Canadian Parks/Recreation Association, 1997). Very few studies, however, have examined family leisure involvement among single-parent families.

Family Leisure and Single-Parent Families

Although previous known-group studies, including families with adopted children (Freeman \& Zabriskie, 2003), and families with a child who has a disability (Mactavish \& Schleien, 1998, 2004; Scholl et al., 2003) have found a positive influence of family leisure on family functioning, researchers have expressed the need for further studies on nontraditional families (Holman \& Epperson, 1984; Zabriskie \& McCormick, 2003), and specifically for a "[broad] national sample of single-parent families [with data collected] from multiple sources, including parents and children within the home" (Smith et al., 2004, p. 53).

A pilot study which consisted of a convenience sample of 46 college students who had grown up for at least two years in a single-parent home found that the single-parent families had lower levels of family functioning and family leisure involvement than traditional families. More specifically they reported less participation in balance family activities, but not less participation in core family activities when compared to 
Family Leisure in Single-Parent Families 17

dual-parent families. It was also found that family leisure involvement and family functioning were highly related and that this relationship appeared to be stronger among single-parent families than dual-parent families (Smith et al., 2004). While findings for this initial study added considerable insight into family leisure among single-parent families, there were several limitations. The sample was relatively small and homogenous in nature. The sample consisted of college students who responded based on memory of being raised in a single-parent family. Authors recommend that data be gathered from a broader, more representative sample of single-parent families, and from multiple perspectives of those living in the home.

Further research using the Core and Balance Model of Family Leisure Functioning as a framework had the potential to impact those who work with families as well as the individuals in the families themselves. It also helped establish a new foundation for future lines of family leisure study, and influence most social sciences that address families. It was anticipated that findings would have significant implications for single-parent families, professionals, services, and agencies that work with such families, and would possibly have provided direction for pro-active intervention strategies. Therefore, the purpose of this study was to examine the contribution of family leisure involvement to the family functioning of single-parent families among a large national representative sample. A secondary purpose was to compare family functioning and family leisure involvement between large national samples of dual and single parent families. 
18 Family Leisure in Single-Parent Families

Hypothesis 1. There would be no difference between single-parent families and dual-parent families in their family functioning and family leisure involvement.

Hypothesis 2. There would be no relationship between core and balance family leisure involvement and family cohesion among single-parent families.

Hypothesis 3. There would be no relationship between core and balance family leisure involvement and family adaptability among single-parent families.

Hypothesis 4. There would be no relationship between core and balance family leisure involvement and overall family functioning among single-parent families.

$$
\text { Methods }
$$

\section{Sample}

The sample consisted of single-parent and dual-parent families with a youth from 11 to 15 years of age. The parent was either a father or mother, and the youth was one dependent child. The restricted age for the youth was implemented to involve children at a cognitive development level with the ability to use abstract thinking necessary for understanding and completing the survey instrument. Psychosocially, children at this age still needed the security of parents and family members, but were beginning to separate themselves from their parents and find their own identity (Zabriskie \& McCormick, 2003). Scholars have emphasized the importance of gathering a family perspective of family functioning, which includes a parent and child perspective (Zabriskie \& Freeman, 2004). In order to gather family members' perspectives of their functioning, this study collected data from a dependent child as well as the parent. This provided two perspectives from each family on their family functioning and leisure. 
Subjects were gathered in cooperation with a sampling company called Survey Sampling International. This company's panel recruitment, management, and usage of practices were all designed to create high quality online sampling. Panelists represented at least two million households across the United States who were recruited through thousands of web sites. Membership on SSI panels is restricted to those who are 18 years of age or older and living in the United States. The nationally representative panel was sent an electronic invitation to participate in this study. If the invitation was accepted, the online questionnaire was sent to them, via its URL, to be completed on their own. The parent answered the first half of the questionnaire and the youth answered the last half, thus the youth and parents were automatically linked together. It was not possible to submit a finished questionnaire until both a parent and a youth responded. At the beginning of the questionnaire, participants read that by completing the questionnaire they were consenting to participate. They were also told that their participation was voluntary, and thus, they could stop at any time. Confidentiality of the participants was ensured as no questions asked for personal identification, though demographic questions were asked. The data were stored on a database and exported to an Excel file that was protected by a password.

Single-Parent Sample. The single-parent family parent sample consisted of 384 parents. Most (227 or 59\%) were divorced, 33 (8.6\%) were separated from their spouse, $32(8.3 \%)$ were widowed, $89(23 \%)$ were never married, and $3(0.78 \%)$ other. The parents ranged in age from 27 to $76(M=42.36, S D=8.07)$ and were predominantly female $(93.2 \%)$ and white $(82.07 \%)$. The sample represented 47 states $(254$ or $66 \%$ urban 
20 Family Leisure in Single-Parent Families

and 130 or $34 \%$ rural) with some from each time zone as follows: Central Standard Time (111 or 29\%), Eastern Standard Time (198 or 52\%), Mountain Standard Time (29 or 7.6\%), and Pacific Standard Time (46 or 12\%). Family size ranged from 2 to 9 family members $(M=3.31, S D=1.25)$ and their annual incomes ranged from less than $\$ 10,000$ (32 or $8.3 \%$ ) to more than $\$ 150,000$ (6 or $1.6 \%$ ), with a median of $\$ 20,000-\$ 29,999$. The length of time the single parents were single was answered by only 141 people $(37 \%)$ and they ranged from less than a year to 29 years with $18.4 \%$ being $1-10$ years and $17.4 \%$ being $11-20$ years.

The youth from the single-parent families ranged in age from 10 to $17(M=$ $13.03, S D=1.48)$ and were predominantly white $(78.9 \%)$ and approximately half were female $(53.5 \%)$. They consisted of $2(0.52 \%)$ foster, $1(0.26 \%)$ step, $9(2.3 \%)$ adopted, and $223(58 \%)$ birth children. The remaining 149 (39\%) did not answer this question. The time the child/children of the single parents spent with the noncustodial parent ranged from $10 \%$ of their time (248 or $64.6 \%$ ) to $100 \%$ of their time (18 or $4.7 \%$ ) with 103 or $26.8 \%$ who spent anywhere from $20 \%-50 \%$ with the noncustodial parent, and 15 or $3.9 \%$ who spent anywhere from $60 \%-90 \%$ with the noncustodial parent.

Dual-Parent Sample. The dual-parent sample consisted of 495 parents with 495 youth. Of these parents, $138(29 \%)$ had been divorced at one time. The parents ranged in age from 24 to $67(M=41.51, S D=6.72)$ and were predominantly female $(86.5 \%)$ and white $(89.9 \%)$. The sample represented 47 states $(254$ or $51 \%$ urban and 130 or $26 \%$ rural) with some from each time zone as follows: Central Standard Time (145 or 29\%), Eastern Standard Time (260 or 52.5\%), Mountain Standard Time (52 or 10.5\%), and 
Family Leisure in Single-Parent Families 21

Pacific Standard Time (38 or 7.7\%). Family size ranged from 1 to 11 family members ( $M$ $=4.48, S D=1.29)$ and their median annual incomes ranged from $\$ 50,000-\$ 59,999$, with a range of less than $\$ 10,000$ (5 or $1 \%$ ) to more than $\$ 150,000(20$ or $4 \%$ ).

The youth from the dual-parent families ranged in age from 10 to $17(M=12.96$, $S D=1.43)$ and were predominantly white $(87.9 \%)$ and approximately half were female $(54.1 \%)$.

\section{Instrumentation}

The questionnaire included three sections: (a) Family Adaptability and Cohesion Scales (FACES II), which provided a measure of the family's perception of their family cohesion, family adaptability, and overall indicators of family functioning (Olson et al., 1992), (b) Family Leisure Activity Profile (FLAP), which provided a measure of core, balance, and overall family leisure involvement (Zabriskie \& McCormick, 2001), and (c) relevant sociodemographic questions.

FACES II. The Family Adaptability and Cohesion Scales includes 30 items used to measure individual perceptions of family cohesion and adaptability. It is also used to calculate family functioning based on Olson's Circumplex Model (Olson, 1986). There are 14 questions that contribute to family adaptability and the other 16 questions refer to family cohesion (Olson, Portner, \& Bell, 1982). The answers were given on a five-point Likert scale from 1 "almost never" to 5 "almost always." Scores for family cohesion and family adaptability were calculated based on a scoring formula that accounted for reverse coded questions. After obtaining total cohesion and total adaptability scores, corresponding $1-8$ values were assigned based on the linear scoring interpretation of 
22 Family Leisure in Single-Parent Families

Olson et al. (1992). These two scores were averaged in order to obtain the family type score which was used as an indicator of overall family functioning. The FACES II scale has acceptable evidence of validity and reliability. Cronbach Alpha coefficients are reported as .78 and .79 for adaptability and .86 and .88 for cohesion (Olson et al., 1992).

FLAP. The Family Leisure Activity Profile measures core and balance family leisure involvement based on the Core and Balance Model of Family Leisure Functioning (Zabriskie, 2000). Eight questions refer to core leisure activities and eight refer to balance activities. In each question, the respondent was given examples of activities. The respondent was then asked if he or she participated in those activities with other family members, and if so, how often and for how long. They also indicate on a five-point Likert scale their satisfaction with their involvement in these family activities $(1=$ very dissatisfied and $5=$ very satisfied).

An index score was found for each question by multiplying duration and frequency. The core index score was found by summing the index scores of questions 18 , and the balance index score was calculated by summing the index scores of questions 9-16. The total family leisure score was calculated by summing the core and balance index scores (Zabriskie \& McCormick, 2001). Acceptable psychometric properties have been reported for the FLAP with evidence of construct validity, content validity, interrater reliability, and test-retest reliability for core $(r=.74)$, balance $(r=.78)$, and total family leisure involvement $(r=.78)$ (Zabriskie, 2001).

Demographics. A series of sociodemographic questions were included to identify underlying characteristics of the sample. These items included age, gender, ethnicity, 
Family Leisure in Single-Parent Families 23

state of residence, population of place residing (urban or rural), annual family income, family size, relationship of parents to all children (i.e., biological, stepparent, adoptive parent), length of time as a single-parent family, reason for single-parent status (divorced, widowed, separated, never married), and percent of time child/children spent with custodial parent.

Analysis

The statistical package SPSS was used to analyze the data. Data were first cleaned, eliminating those questionnaires that had inconsistent responses regarding the same information, implausible responses, outliers, or missing responses. Three data sets were compiled: (a) responses of parents, (b) responses of youth, and (c) family level measurement (the mean for each family). Family cohesion, family adaptability, total family functioning, core leisure involvement, balance leisure involvement, and total family leisure scores were calculated for the three data sets. To examine the differences between the single-parent and dual-parent samples, multiple independent samples $t$ tests were performed. The Bonferroni adjustment was applied to the results due to the use of multiple $t$ tests.

Pearson Product Moment zero-order correlations between variables in each of the three data sets were examined for multicollinearity and identification of possible controlling variables that could be included in subsequent multiple regression equations. Sociodemographic variables which indicated zero-order correlation coefficients with the dependent variables, and those theoretically connected with the dependent variables, were included in the multiple regression models as controlling factors to examine the unique 
24 Family Leisure in Single-Parent Families

contributions of family leisure involvement to family functioning. Three blocked entry multiple regression analyses were run on each dependent variable (family cohesion, family adaptability, and family functioning) from the perspective of the parent, the youth, and the family. These multiple regression models examined the contributions of any significant sociodemographic factors and family leisure involvement to family functioning. The block method was used in each analysis by entering the sociodemographic factors into the first block, and then entering the family leisure variables (core and balance) into the second. The multiple regression coefficients were examined for each model at a .05 alpha level and a Bonferonni adjustment was made on individual tests at a significance level of .01 . The relative contribution of each variable in significant models was determined with standardized regression coefficients (Beta).

\section{Results}

From the single-parent sample, parent cohesion scores on the FACES II ranged from 24 to $80(M=60.91, S D=10.48)$; parent adaptability scores ranged from 20 to 66 $(M=47.35, S D=7.52)$; parent family functioning scores ranged from 1 to $8(M=4.8$, $S D=1.62)$. Youth cohesion scores ranged from 28 to $80(M=58.69, S D=10.88)$; youth adaptability scores ranged from 19 to $66(M=45.07, S D=8.64)$; youth family functioning scores ranged from 1 to $8(M=4.32, S D=1.71)$. These scores are among the FACES II established norms as determined by Olson et al. (1992). The family cohesion scores ranged from 29 to $80(M=59.99, S D=10.02)$; the family adaptability scores ranged from 19.5 to $66(M=46.23, S D=7.39)$; the family sample family functioning scores ranged from 1 to $8(M=4.58, S D=1.55)$. 
Family Leisure in Single-Parent Families 25

The scores from the parent perspective of core family leisure involvement ranged from 5 to $123(M=38.86, S D=17.03)$; parent balance family leisure involvement scores ranged from 0 to $118(M=41.83, S D=23.40)$; parent total family leisure involvement scores ranged from 10 to $200(M=80.69, S D=33.98)$. The scores from the youth perspective of core family leisure involvement ranged from 0 to $94(M=37.83$, $S D=16.81$ ); youth balance family leisure involvement scores ranged from 0 to 263 $(M=45.27, S D=27.02)$; youth total family leisure involvement scores ranged from 0 to $343(M=83.10, S D=37.49)$. The scores from the family perspective of core family leisure involvement ranged from 4.5 to $107.5(M=38.27, S D=15.99)$; the family perspective of balance family leisure involvement scores ranged from 0 to 178 $(M=43.57, S D=23.57)$; the family perspective of total family leisure involvement scores ranged from 5 to $254(M=81.84, S D=33.80)$.

\section{Sample Comparisons}

Comparisons between the single-parent family sample and the dualparent family sample scores of family cohesion, family adaptability, and family functioning, indicated the single-parent cohesion mean scores were slightly lower from the parent, youth, and family perspective, while the adaptability scores were slightly higher, though not statistically significant, from each perspective (see Table 1). Family cohesion was significantly lower $(p<.01)$ for single-parent families from the parent perspective. There were no other significant differences in overall family functioning scores from the parent, youth, or family perspectives. The comparison between the single-parent family sample and the dual-parent family sample scores of core, balance, and total family leisure 
26 Family Leisure in Single-Parent Families

involvement, indicated that all three mean scores were significantly lower among the single-parent family sample from the parent, youth, and family perspectives (see Table 2).

A total of $18 t$ tests were completed to make the comparisons between the two samples. It can be expected that, on average, at least one of the 18 tests would indicate significance strictly by chance if a $<.05$ level of confidence were used for each test (Ramsey \& Schafer, 2002). To prevent this error, a Bonferroni adjustment is often implemented. If the strict application of the Bonferroni adjustment $(p<.00278)$ were applied to this case however, significant results would be obscured, due to eight tests significant at the $<.05$ level that would not meet the Bonferroni adjustment and thus would be eliminated, when it is expected that just one may be significant by chance alone (see Tables $1 \& 2$ ).

Univariate Analyses

Univariate analyses were conducted through zero-order correlations to examine the relationships between family leisure involvement and family functioning among the single-parent sample. Significant relationships $(p<.01)$ were found between the family leisure involvement and family functioning variables in the parent data (see Table 3 ), the youth data (see Table 4) and the family data set (see Table 5). Being the custodial parent was the only significant correlation between family functioning variables and sociodemographic variables among the parent data. Although there were no significant correlations between family functioning variables and sociodemographic variables in the youth data, there were some significant correlations between family leisure variables and 
Family Leisure in Single-Parent Families 27

sociodemographic variables. Being the custodial parent and youth gender were the only significant correlations between family functioning variables and sociodemographic variables in the family perspective data.

\section{Multivariable Analyses}

Multivariable analyses were then run with block method multiple regressions on all three single-parent family data sets (parent, youth, and family) to examine the relationship between family leisure involvement and family functioning beyond the univariate level. In the parent sample (see Table 6) family cohesion was regressed on the independent variables of parent gender, being the custodial parent, parent ethnicity, family size, core leisure involvement, and balance leisure involvement. The first block included only sociodemographic variables and was not a significant model. When core and balance leisure involvement were added to the second block, the model explained a statistically significant change in the variance $\left(\Delta R^{2}=.140, p<.001\right)$. Core family leisure involvement $(\beta=.251, p<.001)$ and balance family leisure involvement $(\beta=.204$, $p<.001)$ were significant predictors of family cohesion while core explained slightly more variance than balance.

Family adaptability (see Table 7) was regressed on the independent variables of parent gender, being the custodial parent, parent ethnicity, family size, core leisure involvement, and balance leisure involvement. The first block included only sociodemographic variables and was not a significant model. When core and balance leisure involvement were added to the second block, the model explained a statistically significant change in the variance $\left(\Delta R^{2}=.135, p<.001\right)$. Core $(\beta=.261, p<.001)$ and 
28 Family Leisure in Single-Parent Families

balance $(\beta=.183, p<.001)$ were significant predictors of family adaptability while core explained more variance than balance.

In the last model from the parent sample (see Table 8), family functioning was regressed on the independent variables of parent gender, being the custodial parent, parent ethnicity, family size, core leisure involvement, and balance leisure involvement. The first block included only sociodemographic variables and was not a significant model. When core and balance leisure involvement were added to the second block, the model explained a statistically significant change in the variance $\left(\Delta R^{2}=.162, p<.001\right)$. Core $(\beta=.286, p<.001)$ and balance $(\beta=.199, p<.001)$ were significant predictors of family functioning while core explained more variance than balance.

In the youth sample (see Table 9) family cohesion was regressed on the independent variables of being the custodial parent, family size, youth gender, youth age, annual income, core leisure involvement, and balance leisure involvement. The first block included only sociodemographic variables and was not a significant model. When core and balance leisure involvement were added to the second block, the model explained a statistically significant change in the variance $\left(\Delta R^{2}=.130, p<.001\right)$. Core $(\beta=.259, p<.001)$ and balance $(\beta=.178, p=.002)$ were significant predictors of family cohesion, while core explained more variance than balance.

Family adaptability (see Table 10) was regressed on the independent variables of being the custodial parent, family size, youth gender, youth age, annual income, core leisure involvement, and balance leisure involvement. The first block included only sociodemographic variables and was not a significant model. When core and balance 
Family Leisure in Single-Parent Families 29

leisure involvement were added to the second block, the model explained a statistically significant change in the variance $\left(\Delta R^{2}=.092, p<.001\right)$. Core $(\beta=.246, p<.001)$ was a significant predictor of family adaptability and balance was not.

In the last model from the youth sample (see Table 11), family functioning was regressed on the independent variables of being the custodial parent, family size, youth gender, youth age, annual income, core leisure involvement, and balance leisure involvement. The first block included only sociodemographic variables and was not a significant model. When core and balance leisure involvement were added to the second block, the model explained a statistically significant change in the variance $\left(\Delta R^{2}=.146\right.$, $p<.001)$. Core $(\beta=.284, p<.001)$ and balance $(\beta=.178, p<.001)$ were significant predictors of family functioning while core explained more variance than balance.

In the final series of multiple regression models, family cohesion, family adaptability, and family functioning were examined from the family perspective. Family cohesion (see Table 12) was regressed on the independent variables of being the custodial parent, youth gender, annual income, core leisure involvement, and balance leisure involvement. The first block included only sociodemographic variables and explained a statistically significant but small amount of variance in family cohesion $\left(\mathrm{R}^{2}=.035\right.$, $p=.005)$. When core and balance leisure involvement were added to the second block, the model explained a statistically significant change in the variance $\left(\Delta R^{2}=.150\right.$, $p<.001)$. Core $(\beta=.295, p<.001)$ and balance $(\beta=.164, p=.003)$ were significant predictors of family cohesion while core explained more variance than balance. 
30 Family Leisure in Single-Parent Families

Family adaptability (see Table 13) was regressed on the independent variables of being the custodial parent, youth gender, annual income, core leisure involvement, and balance leisure involvement. The first block included only sociodemographic variables and was not a significant model. When core and balance leisure involvement were added to the second block, the model explained a statistically significant change in the variance $\left(\Delta R^{2}=.121, p<.001\right)$. Core $(\beta=.292, p<.001)$ was a significant predictor of family adaptability and balance was not.

In the last model from the family sample (see Table 14), family functioning was regressed on the independent variables of being the custodial parent, youth gender, annual income, core leisure involvement, and balance leisure involvement. The first block included only sociodemographic variables and explained a statistically significant but small amount of variance in family functioning $\left(\mathrm{R}^{2}=.038, p=.003\right)$. Being the custodial parent $(\beta=.141, p=.007)$ was a significant predictor. When core and balance leisure involvement were added to the second block, the model explained a statistically significant change in the variance $\left(\Delta R^{2}=.162, p<.001\right)$. Being the custodial parent was no longer a significant predictor. Core $(\beta=.321, p<.001)$ and balance $(\beta=.150$, $p=.006)$ were significant predictors of family functioning while core explained more variance than balance.

\section{Discussion}

Little is known about the contribution of family leisure involvement to family functioning among single-parent families, therefore, the purpose of this study was to compare family functioning and family leisure involvement between large national 
Family Leisure in Single-Parent Families 31

representative samples of dual and single parent families. It was also to examine the contribution of family leisure involvement to the family functioning of single-parent families among this large national representative sample.

Findings indicated some differences among family functioning variables and significant differences in family leisure involvement between single-parent and dualparent family samples. Findings also indicated significant relationships between family leisure and family functioning variables from the parent, youth, and family perspectives in the single-parent sample. Findings added to previous literature and provided further insight into the contribution of family leisure to family functioning among today's singleparent families.

\section{Comparison of Single-Parent Families with Dual-Parent Families}

Much of the large body of research on single-parent families focuses on the problems they face, and is slanted towards discovering what is wrong with them (Olson \& Haynes, 1993; Richards \& Schmiege, 1993). The overall effect of focusing on the negative aspects of these families is the "perpetuation of negative societal stereotypes. Substantial evidence indicates that negative stereotypes affect single parents and their children" (Olson \& Haynes, 1993, p. 260). The findings of this study, however, contradict some of the negative stereotypes. When comparing specific measures of family functioning between single-parent and dual-parent families, there were limited differences. This lack of empirical difference between two national samples suggests that single-parent families may not function as poorly as much of the previous literature suggests. While single-parent families do face tremendous challenges, it cannot be 


\section{Family Leisure in Single-Parent Families}

assumed that they will not succeed, and that they will automatically function much lower than dual-parent families based solely on their structure.

When comparing family functioning variables between the single-parent families and the dual-parent families, findings indicated that the only statistically significant difference was in perceptions of family cohesion. Lower family cohesion among singleparent families was reported from both the parent and family perspective. No other significant differences were found in family functioning among the parent, youth, or family perspectives between the two samples. These findings provide empirical evidence that support the "attempt to change damaging stereotypes of single parents and children by focusing on the strengths of single-parent families" (Olson \& Haynes, 1993, p. 260). They also support the call "to go beyond the negative, pathological view of single-parent families to begin to identify and build on some of the strengths such families can have" (Richards \& Schmiege, 1993, p. 277).

Current findings also contradicted those reported in a pilot study (Smith et al., 2004) that examined differences between single and dual-parent families. Smith et al. reported that single-parent families were lower than dual-parent families in reported family cohesion, adaptability, and overall family functioning. Their sample consisted of college students who were raised in single-parent families. Interestingly, those who responded by memory after being raised in a single-parent home reported greater differences in family functioning when compared to dual-parent families than those currently living in a single-parent home. This may be explained by the findings of Olson and Haynes (1993) and Richards and Schmiege (1993) when they interviewed single 
Family Leisure in Single-Parent Families 33

parents who reported much pride in their single-parenting skills and independence. No bitterness or self-pity was detected, only warmth, pride and compassion. Parents and youth in the current sample were living in single-parent situations and may have responded more positively in an effort to contradict negative stereotypes when being questioned about their current family behaviors. On the other hand, although the youngadult sample were reporting from memory, which may have affected their responses, the fact that they were no longer in the single-parent household may also have provided them with a more accurate perspective and/or greater insight into the impact of being raised in a single-parent family.

Another difficulty mentioned by single-parents in the study by Richards and Schmiege (1993) was that children often became more challenging to manage over time, mainly due to adolescence. Furthermore, many other studies that report negative effects of single-parent families do so by reporting on negative adolescent behaviors such as exhibiting high levels of emotional problems and underperforming in school (Moore \& Vandivere, 2000), using illegal substances and having early contact with police (McLanahan \& Sandefur, 1994). The majority of youth respondents in the current sample, however, were in early adolescence $(M=13.03, S D=1.48)$ and may be just beginning to experience such challenges and behaviors. This may help explain the lack of differences between single and dual-parent families in aspects of family functioning reported by the youth in this sample. It may also help explain why the differences that were reported in current findings were from the parents who were not only those providing and caring for their families, but may also have older adolescents in the home. 
34 Family Leisure in Single-Parent Families

When comparing family leisure between single-parent and dual-parent families, the single-parent families reported less involvement in core and balance family leisure activities and thus less total family leisure from the parent, youth, and family perspectives. Considering the unique situations facing single-parent families regarding financial difficulties (Garfinkle \& McLanahan, 1986) and time constraints (Cooney \& Mortimer, 1999), the fact that they participate in less family leisure can be expected. From the youth perspective, however, the difference between single and dual-parent families particularly in core family leisure involvement was not significant when applying the Bonferroni adjustment. These findings are consistent with findings of Smith et al. (2004) when examining young adults who were raised in single-parent families. They reported significant differences in balance and overall family leisure involvement but no significant difference in participation in core family leisure activities. They concluded that such results supported previous research that identified the essential nature of core family leisure involvement particularly among youth respondents. Current findings add additional support to this concept as well as suggest that although there are clear and expected differences in the amount of family leisure involvement, single-parent families clearly do participate in both core and balance family leisure not withstanding constraints inherent to their family structure.

It is also interesting to note that single-parent families reported significantly less involvement in balance types of family leisure from all three perspectives while also reporting slightly higher levels of family adaptability than dual-parent families. Past literature has reported a direct relationship between these two variables among traditional 
Family Leisure in Single-Parent Families 35

families (Zabriskie \& McCormick, 2001; Zabriskie, 2002). In other words, it has been suggested that the novelty and challenge inherent to balance types of family leisure are likely to facilitate and foster flexibility and adaptive skills among typical families. When considering the requirements of balance family activities which often require more time, effort, and money, and usually take place away from home, it would be expected that single-parent families would participate less. Single-parent families are more than twice as likely to have stressful family environments than dual-parent families (Moore \& Vandivere, 2000) due to financial difficulties and lack of time challenges. Although such constraints may explain the low involvement in balance family leisure activities in this sample, it may also be due to a lower priority of the need for further development of adaptive skills among single-parent families.

Perhaps the explanation of these specific findings may be discovered in the complications and difficult circumstances that typically accompany single-parent families. The very nature of their family structure presents experiences of novelty, challenge, and change as part of their everyday life. Single-parent families are commonly involved in challenging situations such as, ex-spouse complications, child care decisions, moving, role and task overload, lack of sleep and leisure time, and dealing with negative stereotypes. They must develop the skills necessary to cope with extensive challenges, thus growing and adapting in order to exist and remain a functioning family unit. It is likely that while they do participate in balance types of family leisure, the contribution of these kinds of activities to the development of adaptive family skills is less necessary among single-parent families. Thus, single-parent families are likely to be quite adaptive 
36 Family Leisure in Single-Parent Families

and flexible while still having a considerable need to develop relationships and family closeness or cohesion typically related to core types of family leisure involvement. Gaining an understanding of the nature of the relationship between family leisure involvement and family functioning among these families should add further insight into the role of family leisure specifically for single-parent families.

\section{Relationship of Family Leisure Involvement and Family Functioning}

A positive relationship between family leisure patterns and successful family functioning has consistently been found among families (Hawks, 1991; Holman \& Epperson, 1989; Orthner \& Mancini, 1991; Zabriskie \& McCormick, 2001). Studies have also reported a positive relationship of family leisure involvement and family functioning among families with different family structures, including special-needs adoptive families and families with a child who has a disability (Freeman \& Zabriskie, 2003; Mactavish, \& Schleien, 1998; Mactavish, \& Schleien, 2004; Scholl et al., 2003). Recent studies (Smith, et al., 2004; Taylor, et al., 2004) suggest there may be a strong relationship between family leisure and family functioning among single-parent families, which this study indicates as well.

Findings supported previous research (Smith, et al., 2004) by reporting significant relationships between family leisure variables and family functioning variables among single-parent families. Furthermore, findings indicated a positive multivariable relationship between family leisure and family functioning for this broad national sample of single-parent families whether considered from a parent $(p<.01)$, youth $(p<.01)$, or family $(p<.01)$ perspective. In other words, when other family characteristics were 
Family Leisure in Single-Parent Families 37

considered as possible predictors of family functioning, characteristics such as age, gender, ethnicity, family size, being the custodial parent, and annual income, family leisure involvement was the only significant predictor of family cohesion, adaptability, and overall family functioning.

Previous studies among traditional families have consistently reported core family leisure involvement as contributing primarily to the explanation of family cohesion while balance leisure involvement has contributed primarily to family adaptability. Furthermore, parents from traditional family samples have reported relatively equal contribution of both core and balance family leisure to the explanation of aspects of family functioning while youth from such samples reported a greater contribution of core family leisure involvement to the explanation of family functioning (Zabriskie \& Freeman, 2004; Zabriskie \& McCormick, 2001). Findings from the current single-parent family sample, however, indicated that both core and balance family leisure involvement contributed to the explanation of both family cohesion and adaptability whether measured from the parent, youth, or family perspectives. Furthermore, core family leisure involvement contributed to the explanation of more variance in all indicators of family functioning from not only the youth perspective but from the parent and family perspectives as well. This is among the first studies in which core family leisure explained more variance than balance family leisure in family functioning from the parent and family perspectives and is likely due to the nature of the single-parent family structure. 
38 Family Leisure in Single-Parent Families

Although single-parent families report less participation in both core and balance family leisure than traditional families, it is likely that core activities contribute more to aspects of family functioning based primarily on their simple, common, everyday, nature and that they are more accessible to single-parent families. While these families do report participation in balance types of family activities, it is likely that there are more constraints to be negotiated due to their nature which typically require more time, effort, and money. As mentioned previously, such balance activities provide opportunities for traditional families to be challenged and stretched in a leisure context and are likely to help develop adaptive family skills. Single-parent families, however, are likely to have previously developed such skills due to daily life experiences and may have less need for such challenges in their leisure activities. The need for consistent time together participating in regular home-based core family activities such as reading, eating dinner, playing games, cooking, and simply relaxing together, however, appears to be necessary when considering family functioning among single-parent families.

It is also interesting to note that although single-parent families participated in less family leisure when compared to dual-parent families, they functioned similarly. Considering that family leisure involvement was the only significant predictor in regression models that explained $12 \%$ to $20 \%$ of the variance in measures of family functioning among single-parent families suggests that family leisure plays a significant role in single-parent households. When considering additional challenges related to single-parent families such as work demands, time constraints, legal and custody issues, 
Family Leisure in Single-Parent Families 39

negative stereotypes, etc... it is possible that family leisure involvement plays an even greater role among these families than for dual-parent families.

Findings from this study add further support to the body of literature that has reported significant relationships between family leisure involvement and family functioning and has added to the usefulness and construct validity of the Core and Balance Model which suggests a direct relationship between these two variables (Zabriskie \& McCormick, 2001). This study supports the continued use of this model as a foundation for research regarding family leisure implying that it offers "the necessary framework to further test and understand the nature of the family leisure relationship" (Zabriskie \& McCormick, 2001, p. 288).

Findings from this study also contribute to the literature by responding to calls for family leisure research among nontraditional families and specifically among singleparent families. Findings support the existing single-parent research by confirming significant correlations between family leisure and family functioning. They also provide additional insight by collecting data from a large national sample of parents and youth currently in single-parent homes and by making direct comparisons with a large dualparent sample gathered at the same time. Among such insight is the critical nature of core family leisure involvement among single-parent families. This is also among the first studies to report similarities between dual and single parent families with a direct measure of family functioning and it did so from a parent, child, and family perspective. 
40 Family Leisure in Single-Parent Families

Recommendations for Future Research

There are several implications for future study among single-parent families based on current findings. First, it must be recognized that family leisure involvement is an essential component of single-parent family life and is a behavioral characteristic that has been empirically correlated to higher family functioning among these families.

Furthermore, involvement in regular, everyday, home-based, core family leisure types of activities clearly plays a significant role when considering family functioning among single-parent families. Therefore, future research among single-parent families not only should continue to examine aspects of family leisure but should also focus specifically on the meaning and role of core family leisure involvement.

Second, when considering that single-parent families reported less family leisure involvement and similar levels of family functioning when compared to dual-parent families; it may be beneficial to examine the quality of their family leisure. It is recommended that future study examine variables such as core and balance leisure satisfaction and other quality of life variables such as satisfaction with family life among single-parent families. Qualitative approaches to examining the meaning and quality of family leisure among single-parent families is also recommended and will likely add further insight into both the quality and the core leisure involvement questions.

Third, this is perhaps the first study to report that there are more similarities than differences in aspects of family functioning between single-parent and dual-parent families. It is also the first study to make direct empirical comparisons between two national samples and to do so from parent, child, and family perspectives. Therefore, it is 
Family Leisure in Single-Parent Families 41

recommended that future research confirm these findings and endeavor to do so with direct comparisons from multiple perspectives within the family unit. Such methods are also recommended when examining other family variables among both single and dual parent families.

While findings add considerable insight to the body of knowledge and provide clear direction for future research, some limitations of the current study must also be acknowledged. Data were collected via an online questionnaire and,therefore, limited respondents to single and dual-parent families who had access to the internet. This may have biased the research by gathering data from families of a higher socioeconomic status than those of a lower status. It is likely that there are many single-parent families who do not have access to the internet whose responses may have added further insight to current findings but were not included in this sample. It is recommended that future research among single-parent families make an effort to access such families. It is also possible this research was biased due to self-selected respondents who may be higher educated than most single-parents.

It must be acknowledged that while these findings are slightly unexpected regarding single-parent families functioning much like dual-parent families, the extreme difficulties and challenges they face, due to their family structure, cannot be discounted or ignored. It should also be acknowledged that this study utilized correlational techniques to identify relationships and, therefore, interpretation related to the directionality of relationships cannot be made without further research. 
42 Family Leisure in Single-Parent Families

Longitudinal studies approaching experimental designs must be conducted in order to assess causality in the family leisure and family functioning relationship. 
Family Leisure in Single-Parent Families 43

\section{References}

Broderick, C. B. (1993). Understanding family process: Basics of family systems theory. Thousand Oaks, CA: Sage.

Brody, G. H., \& Flor, D. L. (1997). Maternal psychological functioning, family processes, and child adjustment in rural, single-parent, African American families. Developmental Psychology 33(6), 1000-1012.

Canadian Parks/Recreation Association (1997). The benefits catalogue. Gloucester, Ontario, Canada: Author.

Christenson, O., Zabriskie, R., Eggett, D., \& Freeman, P. (2006). Family acculturation, family leisure involvement, and family functioning among Mexican-Americans. Journal of Leisure Research, 38(4), 475-495.

Cooney, T. M., \& Mortimer, J. T. (1999). Family structure differences in the timing of leaving home: Exploring mediating factors. Journal of Research on Adolescence, $9(4), 367-394$.

Dodd, D. C. H. (2007). Contributions of family leisure to family functioning among families that include children with developmental disabilities. Unpublished masters thesis, Brigham Young University, Provo, Utah, U.S.A.

Erich, S., \& Leung, P. (1998). Factors contributing to family functioning of adoptive children with special needs: A long term outcome analysis. Children and Youth Services Review, 20, 135-150.

Family Discipleship Ministries. (2002.) Alarming statistics. Retrieved September 19, 2003, from http://www.parentingministry.org/Alarming_Statististis.htm. 
44 Family Leisure in Single-Parent Families

Freeman, P., \& Zabriskie, R. B. (2003). Leisure and family functioning in adoptive families: Implications for therapeutic recreation. Therapeutic Recreation Journal, $37(1), 73-93$.

Garanzini, M. J. (1995). Child-centered, family-sensitive schools: An educator's guide to family dynamics. Washington, DC: National Catholic Educational Association.

Garfinkle, I., \& McLanahan, D. (1986). Single mothers and their children: A new American dilemma. Washington, DC: Urban Institute Press.

Greif, G. L. (1996). Treating the changing single-parent family: A return to boundaries. Children Today, 24(1), 19-22.

Hawks, S. R. (1991). Recreation in the family. In S. J. Bahr (Ed.), Family research: A sixty year review, 1930-1990 (pp. 387-433). New York: Lexington Books.

Hoffman, S. D., \& Duncan, G. J., (1988). What are the economic consequences of divorce? Demography, 25(64), 1-45.

Holman, T. B. \& Epperson, A. (1984). Family and leisure: A review of the literature with research recommendations. Journal of Leisure Research, 16, 277-294.

Holman, T. B., \& Epperson, A. (1989). Family and leisure: A review of the literature with research recommendations. Journal of Leisure Research, 16, 277-294.

Huff, C., Widmer, M., McCoy, K., \& Hill, B. (2003). The influence of challenging outdoor recreation on parent-adolescent communication. Therapeutic Recreation Journal, 37(1), 18-37. 
Family Leisure in Single-Parent Families 45

Iso-Ahola, S. E. (1984). Social psychological foundations of leisure and resultant implications for leisure counseling. In E. T. Dowd (Ed.), Leisure counseling: Concepts and applications (pp. 97-125). Springfield, IL: Charles C. Thomas.

Kelly, J. R. (1996). Leisure (3rd ed.). Needham Heights, MA: Allyn \& Bacon.

Kelly, J. R. (1999). Leisure behaviors and styles: Social, economic, and cultural factors. In E. L. Jackson \& T. L. Burton (Eds.), Leisure studies: Prospects for the twentyfirst century (pp. 135-150). State College, PA: Venture.

Mactavish, J., \& Schleien, S. (1998). Playing together growing together: Parents' perspectives on the benefits of family recreation in families that include children with a developmental disability. Therapeutic Recreation Journal, 32(3), 207-230.

Mactavish, J., \& Schleien, S. (2004). Re-injecting spontaneity and balance in family life: parents' perspective on recreation in families that include children with developmental disability. Journal of Intellectual Disability Research 48(2), 123 141.

McLanahan, S., \& Sandefur, G. (1994). Growing up with a single parent. Cambridge: Harvard University Press.

Moore, K. A., \& Vandivere, S. (2000). Stressful family lives: Child and parent wellbeing. New Federalism: National Survey of America's Families (B), B-17.

Olson, D. H. (1986). Circumplex model VII: Validation studies and FACES III. Family Process, 25, 337-351. 
46 Family Leisure in Single-Parent Families

Olson, D. H. (1993). Circumplex model of marital and family systems: Assessing family systems. In F. Walsh (Ed.), Normal Family Processes (pp. 104-137). New York: Guilford Press.

Olson, D. H., McCubbin, H. I., Barnes, H., Larsen, A., Muxen, M., \& Wilson, M. (1992). Family inventories: 2nd Revision. St. Paul, MN: University of Minnesota.

Olson, D. H., Portner, J., \& Bell, R. (1982). FACES II: Family adaptability and cohesion evaluation scales. St. Paul, MN: Family Social Science, University of Minnesota.

Olson, M. R., \& Haynes, J. A. (1993). Successful single parents. Families in Society, $74(5), 259-268$.

Orthner, D. K., \& Mancini, J. A. (1990). Leisure impacts on family interaction and cohesion. Journal of Leisure Research, 22(2), 125-137.

Orthner, D. K., \& Mancini, J. A. (1991). Benefits of leisure for family bonding. In B. L. Driver, P. J. Brown, \& G. L. Peterson (Eds.), Benefits of leisure (pp. 215-301). State College, PA: Venture.

Ramsey, F. L. \& Schafer, D. W. (2002). The statistical sleuth: A course in methods of data analysis (2nd Ed.). Pacific Grove, CA: Duxbury.

Richards, L. N., \& Schmiege, C. J. (1993). Problems and strengths of single-parent families: Implications for practice and policy. Family Relations, 42(3), 277-285.

Scholl, K., McAvoy, L., Rynders, J., \& Smith, J. (2003). The influence of inclusive outdoor recreation experience on families that have a child with a disability. Therapeutic Recreation Journal, 37(1), 38-57. 
Family Leisure in Single-Parent Families 47

Smith, K. M., Taylor, S., Hill, B., \& Zabriskie, R. B. (2004). Family functioning and leisure in single-parent families. Abstracts from the 2004 Leisure Research Symposium. Ashburn, VA: National Recreation and Parks Association, 53.

Taylor, S., Zabriskie, R. B., Smith, K. M., \& Hill, B. J. (2004). Family leisure functioning in single-parent families: A preliminary study. Proceedings of the Annual Conference of the National Council on Family Relations, Orlando, FL.

U. S. Bureau of the Census. (1992). Census of the population: General population characteristics, United States: 1990. Washington, DC: U. S. Government Printing Office.

Wallerstein, J., Lewis, J. M., \& Blakeslee, S. (2000). The unexpected legacy of divorce. New York: Hyperion.

Wells, M. S., Widmer, M. A., \& McCoy, J. K. (2004). Grubs and grasshoppers: Challenge-based recreation and the collective efficacy of families with at-risk youth. Family Relations, 53(3), 326-333.

Zabriskie, R. B. (2000). An examination of family and leisure behavior among families with middle school aged children. Unpublished doctoral dissertation, Indiana University, Bloomington.

Zabriskie, R. B. (2001). The validity and reliability of the Family Leisure Activity Profile (FLAP). In M. E. Havitz, \& M. F. Floyd (Eds.), Abstracts of the 2001 Symposium on Leisure Research (p. 66). Ashburn, VA: National Recreation and Park Association. 
48 Family Leisure in Single-Parent Families

Zabriskie, R. B. (2002). Research into action: Focus on families. Leisure Insights, 22(1), 10.

Zabriskie, R. B., \& Freeman, P. (2004). Contributions of family leisure to family functioning among transracial adoptive families. Adoption Quarterly, 7(3), 49-77.

Zabriskie, R. B., \& McCormick, B. (2001). The influences of family leisure patterns on perceptions of family functioning. Family Relations: Interdisciplinary Journal of Applied Family Studies, 50(3), 281-289.

Zabriskie, R. B., \& McCormick, B. P. (2003). Parent and child perspectives of family leisure involvement and satisfaction with family life. Journal of Leisure Research, 35(2), 163-189. 
Family Leisure in Single-Parent Families 49

Table 1

Differences between Single-Parent Families and Dual-Parent Families on Cohesion, Adaptability, and Family Functioning

\begin{tabular}{|c|c|c|c|c|}
\hline Variable & $\mathbf{M}$ & SD & $\mathbf{t}$ & $p$ \\
\hline \multicolumn{5}{|l|}{ Parent Perspective } \\
\hline \multicolumn{5}{|l|}{ Cohesion } \\
\hline Single-Parent $(\mathrm{n}=384)$ & 60.91 & 10.48 & -3.80 & $<.001 * *$ \\
\hline Dual-Parent $(\mathrm{n}=495)$ & 63.46 & 9.361 & -3.74 & $<.001 * *$ \\
\hline \multicolumn{5}{|l|}{ Adaptability } \\
\hline Single-Parent & 47.35 & 7.517 & .429 & .668 \\
\hline Dual-Parent & 47.14 & 6.890 & .424 & .672 \\
\hline \multicolumn{5}{|l|}{ Family Functioning } \\
\hline Single-Parent & 4.807 & 1.620 & -1.66 & .098 \\
\hline Dual-Parent & 4.985 & 1.543 & -1.65 & .100 \\
\hline \multicolumn{5}{|l|}{ Youth Perspective } \\
\hline \multicolumn{5}{|l|}{ Cohesion } \\
\hline Single-Parent $(\mathrm{n}=384)$ & 58.69 & 10.88 & -1.38 & .168 \\
\hline Dual-Parent $(n=495)$ & 59.70 & 10.26 & -1.37 & .171 \\
\hline \multicolumn{5}{|l|}{ Adaptability } \\
\hline Single-Parent & 45.07 & 8.638 & 2.24 & $.025^{*}$ \\
\hline Dual-Parent & 43.75 & 8.405 & 2.23 & $.026^{*}$ \\
\hline \multicolumn{5}{|l|}{ Family Functioning } \\
\hline Single-Parent & 4.319 & 1.709 & .611 & .541 \\
\hline Dual-Parent & 4.247 & 1.663 & .609 & .543 \\
\hline \multicolumn{5}{|l|}{ Family Perspective } \\
\hline \multicolumn{5}{|l|}{ Cohesion } \\
\hline Single-Parent $(\mathrm{n}=384)$ & 59.988 & 10.02 & -2.57 & $.010^{*}$ \\
\hline Dual-Parent $(\mathrm{n}=495)$ & 61.70 & 9.275 & -2.54 & $.011^{*}$ \\
\hline \multicolumn{5}{|l|}{ Adaptability } \\
\hline Single-Parent & 46.23 & 7.389 & 1.54 & .124 \\
\hline Dual-Parent & 45.46 & 7.007 & 1.53 & .127 \\
\hline \multicolumn{5}{|l|}{ Family Functioning } \\
\hline Single-Parent & 4.582 & 1.554 & -.440 & .660 \\
\hline Dual-Parent & 4.629 & 1.500 & -.438 & .662 \\
\hline
\end{tabular}

Note. ${ }^{*} p<.05 ; * * p<.01$ 
50 Family Leisure in Single-Parent Families

Table 2

Differences between Single-Parent Families and Dual-Parent Families on Family

Leisure Patterns

Variable

M

SD

t p

Parent Perspective

Core Activities

Single-Parent $(n=384)$

Dual-Parent $(n=495)$

38.86

43.26

17.03

Balance Activities

Single-Parent

41.83

Dual-Parent

49.30

24.00

80.69

33.98

Single-Parent

Dual-Parent

92.56

34.60

$\begin{aligned}-3.89 & <.001^{* *} \\ -3.87 & <.001^{* *} \\ & \\ -4.63 & <.001^{* *} \\ -4.64 & <.001^{* *} \\ & \\ -5.08 & <.001^{* *} \\ -5.09 & <.001^{* *}\end{aligned}$

Youth Perspective

Core Activities

Single-Parent $(\mathrm{n}=384)$

Dual-Parent $(\mathrm{n}=495)$

Balance Activities

Single-Parent

Dual-Parent

Total Family Leisure

Single-Parent

Dual-Parent

37.83

40.38

16.81

16.45

$-2.22 \quad .027^{*}$

$-2.21 \quad .027 *$

45.27

27.02

$-2.52 .012^{*}$

49.85

25.68

$-2.50 .013^{*}$

83.10

37.49

36.12

$-2.80 \quad .005 * *$

90.23

$-2.79 .005^{* *}$

Family Perspective

Core Activities

Single-Parent $(\mathrm{n}=384)$

38.27

Dual-Parent $(\mathrm{n}=495)$

41.86

15.99

14.98

$-3.35 \quad .001^{* *}$

Balance Activities

Single-Parent

43.57

23.57

23.53

$-3.32 \quad .001 * *$

Dual-Parent

Total Family Leisure

49.64

$-3.71<.001 * *$

$-3.71<.001^{* *}$

Single-Parent

81.84

33.80

Dual-Parent

91.51

33.24

$-4.16<.001^{* *}$

$-4.15<.001 * *$

Note. ${ }^{*} p<.05 ;{ }^{* *} p<.01$ 
Family Leisure in Single-Parent Families 51

Table 3

Zero Order Pearson Correlations: Parent Data

\begin{tabular}{|c|c|c|c|c|c|c|c|c|c|c|c|c|c|c|}
\hline & Core & Balance & FLTotal & Cohes & Adapt & Famfunc & CuParent & Gender & FamSize & Ethnicity & Time S-P & TimeN-P & P-Age & Income \\
\hline Core & 1 & $.398 * *$ & $.775^{* *}$ & $.326^{* *}$ & $.335 * *$ & $.359 * *$ & .050 & -.041 & $.139^{*}$ & -.085 & .015 & -.063 & -.085 & .151 \\
\hline Balance & & 1 & $.888^{* *}$ & $.311 * *$ & $.289 * *$ & $.315 * *$ & .063 & -.078 & .063 & .095 & -.028 & .016 & -.012 & .261 \\
\hline FLTotal & & & 1 & $.378 * *$ & $.366^{* *}$ & $.397 * *$ & .069 & -.074 & $.113^{*}$ & .023 & -.012 & -.021 & -.051 & .206 \\
\hline Cohes & & & & 1 & $.651^{* *}$ & $.914 * *$ & $.118^{*}$ & .083 & .026 & .070 & -.027 & -.029 & .030 & .030 \\
\hline Adapt & & & & & 1 & $.862 * *$ & $.120 * *$ & .055 & .033 & .018 & .054 & -.067 & -.003 & .051 \\
\hline Famfunc & & & & & & 1 & $.126^{* *}$ & .092 & .020 & .045 & .014 & -.022 & .035 & .046 \\
\hline CuParent & & & & & & & 1 & $.245^{* *}$ & .064 & -.057 & -.078 & .173 & .127 & .161 \\
\hline Gender & & & & & & & & 1 & .045 & -.072 & .106 & -.129 & -.077 & -.198 \\
\hline FamSize & & & & & & & & & 1 & $-.163 * *$ & -.015 & .034 & -.097 & .024 \\
\hline Ethnicity & & & & & & & & & & 1 & -.007 & -.011 & .106 & -.002 \\
\hline Time S-P & & & & & & & & & & & 1 & -.021 & .288 & -.002 \\
\hline Time N-P & & & & & & & & & & & & 1 & -.010 & .072 \\
\hline P-Age & & & & & & & & & & & & & 1 & -.006 \\
\hline Income & & & & & & & & & & & & & & 1 \\
\hline
\end{tabular}

Note . Core $=$ core family leisure patterns; Balance $=$ balance family leisure patterns; FLTotal $=$ total family leisure involvement; Cohes $=$ family cohesion; Adapt $=$ family adaptability; Famfunc $=$ family functioning; CuParent = custodial parent of youth; Gender = parent gender; FamSize = total number of immediate family members; Ethnicity = ethnicity of parent; Time S-P = how long been singleparent; Time N-P = \% time child with noncustodial parent; P-Age = parent age; Income $=$ Annual Income. $*=p<.05 ; * *=p<.01$ 


\section{Family Leisure in Single-Parent Families}

Table 4

Zero Order Pearson Correlations: Youth Data

\begin{tabular}{|c|c|c|c|c|c|c|c|c|c|c|c|c|c|c|c|}
\hline & Core & Balance & FLtotal & Cohes & Adapt & Famfunc & CuParent & FamSize & Gender & Y-Age & Income & TimeS-P & TimeN-P & Pop & Y-Ethnic \\
\hline Core & 1 & $.432 * *$ & $.760 * *$ & $.351 * *$ & $.305 * *$ & $.372^{* *}$ & $-.123^{* *}$ & $.133^{* *}$ & .058 & $-.200 * *$ & .035 & .006 & -.121 & .009 & -.077 \\
\hline Balance & & 1 & $.915^{* *}$ & $.300 * *$ & $.245 * *$ & $.316^{* *}$ & -.078 & .038 & .039 & .007 & $.198 * *$ & -.141 & .011 & .030 & .049 \\
\hline FL Total & & & 1 & $.373 * *$ & $.313 * *$ & $.394 * *$ & $-.111^{*}$ & .087 & .054 & -.084 & $.158^{* *}$ & -.100 & -.046 & .026 & .001 \\
\hline Cohes & & & & 1 & $.586 * *$ & $.892 * *$ & .090 & .009 & .086 & -.098 & .073 & -.043 & .000 & -.100 & -.002 \\
\hline Adapt & & & & & 1 & $.833 * *$ & .081 & .084 & .092 & .021 & .062 & -.103 & -.057 & -.039 & -.060 \\
\hline Famfunc & & & & & & 1 & .098 & .026 & .099 & -.048 & .069 & -.097 & -.021 & -.072 & -.037 \\
\hline CuParent & & & & & & & 1 & -.064 & -.005 & -.096 & $-.161 * *$ & -.078 & .173 & -.082 & .018 \\
\hline FamSize & & & & & & & & 1 & .034 & -.023 & .024 & -.015 & .034 & .090 & .141 \\
\hline Gender & & & & & & & & & 1 & -.016 & -.010 & -.060 & -.033 & .055 & .030 \\
\hline Y-Age & & & & & & & & & & 1 & -.045 & -.019 & .041 & .115 & .073 \\
\hline Income & & & & & & & & & & & 1 & -.002 & .072 & -.200 & -.011 \\
\hline Time S-P & & & & & & & & & & & & 1 & -.021 & .054 & -.127 \\
\hline Time N-P & & & & & & & & & & & & & 1 & -.062 & -.030 \\
\hline Pop & & & & & & & & & & & & & & 1 & .112 \\
\hline Y-Ethnic & & & & & & & & & & & & & & & 1 \\
\hline
\end{tabular}

Note . Core $=$ core family leisure patterns; Balance $=$ balance family leisure patterns; FLTotal $=$ total family leisure involvement; Cohes $=$ family cohesion; Adapt $=$ family adaptability; Famfunc $=$ family functioning; CuParent = custodial parent of youth; FamSize = total number of immediate family members; Gender = youth gender; Y-Age = youth age; Income = annual income of family; Time S-P = how long been single-parent; Time N-P $=\%$ time child with noncustodial parent; Pop $=$ population of place of residence; Y-Ethinc $=$ youth ethnicity. $*=p<.05 ; * *=p<.01$ 
Family Leisure in Single-Parent Families 53

Table 5

Zero Order Pearson Correlations: Family Data (Parent and Youth)

\begin{tabular}{|c|c|c|c|c|c|c|c|c|c|c|c|c|c|c|c|}
\hline & Core & Balance & FLtotal & Cohes & Adapt & Famfunc & CuParent & Income & Gender & TimeS-P & TimeN-P & FamSize & Pop & P-Age & Y-Ethnic \\
\hline Core & 1 & $.439 * *$ & $.779 * *$ & $.382 * *$ & $.356 * *$ & $.405^{* *}$ & -.091 & .033 & .097 & .382 & -.109 & .132 & .029 & -.186 & -.077 \\
\hline Balance & & 1 & $.905 * *$ & $.310 * *$ & $.260 * *$ & $.312^{* *}$ & -.077 & $.217 * *$ & .072 & .310 & .003 & .032 & .040 & -.018 & .064 \\
\hline FL Total & & & 1 & $.397 * *$ & $.350 * *$ & $.409^{* *}$ & -.097 & $.167 * *$ & .096 & .397 & -.050 & .085 & .041 & -.100 & .008 \\
\hline Cohes & & & & 1 & $.657 * *$ & $.918^{* *}$ & $.117 *$ & .060 & $.121^{*}$ & -.046 & -.012 & .017 & -.086 & -.074 & .025 \\
\hline Adapt & & & & & 1 & $.861^{* *}$ & $.110^{*}$ & .065 & .090 & -.048 & $\begin{array}{l}-062 \\
\end{array}$ & .071 & -.032 & .036 & -.029 \\
\hline Famfunc & & & & & & 1 & $.124 *$ & .065 & $.119 *$ & -.057 & -.018 & .027 & -.056 & -.028 & -.009 \\
\hline CuParent & & & & & & & 1 & $-.161 * *$ & -.005 & \begin{tabular}{|l|}
-.078 \\
\end{tabular} & .173 & .064 & -.082 & .096 & .018 \\
\hline Income & & & & & & & & 1 & -.010 & -.002 & .072 & .024 & -.200 & -.045 & -.011 \\
\hline Gender & & & & & & & & & 1 & $\begin{array}{l}.060 \\
\end{array}$ & $\begin{array}{l}-033 \\
\end{array}$ & .034 & .055 & -.016 & .030 \\
\hline Time S-P & & & & & & & & & & 1 & -.021 & -.015 & .054 & -.019 & -.127 \\
\hline TimeN-P & & & & & & & & & & & 1 & .034 & -.062 & .041 & -.030 \\
\hline FamSize & & & & & & & & & & & & 1 & .090 & -.023 & -.141 \\
\hline Pop & & & & & & & & & & & & & 1 & .115 & .112 \\
\hline P-Age & & & & & & & & & & & & & & 1 & .073 \\
\hline Y-Ethnic & & & & & & & & & & & & & & & 1 \\
\hline
\end{tabular}

Note Core $=$ core family leisure patterns; Balance $=$ balance family leisure patterns; FLTotal $=$ total family leisure involvement; Cohes $=$ family cohesion; Adapt $=$ family adaptability; Famfunc $=$

family functioning; CuParent = custodial parent of youth; Income = annual income of family; Gender = youth gender; Time S-P = how long been single-parent; Time N-P= $\%$ time child with noncustodial parent; FamSize $=$ total number of immediate family members; Pop $=$ population of place of residence; $\mathrm{P}$-Age $=$ parent age; Y-Ethnic $=$ youth ethnicity. $*=p<.05 ; * *=p<.01$ 
54 Family Leisure in Single-Parent Families

Table 6

Summary of Blocked Regression Equations Predicting Family Cohesion: Parent Data

\begin{tabular}{llccc}
\hline Predictor & B & SE B & $\boldsymbol{\beta}$ & $\boldsymbol{p}$ \\
\hline & & & & \\
Block $1 \mathrm{R}^{2}=.027\left(p=.038^{*}\right)$ & & & & \\
& & & & \\
Parent Gender & 2.514 & 2.196 & .060 & .253 \\
Custodial Parent & 4.970 & 2.376 & .111 & $.037^{*}$ \\
Parent Ethnicity & 2.641 & 1.430 & .096 & .066 \\
Family Size & .403 & .437 & .048 & .357 \\
& & & & \\
Block 2 $\Delta \mathrm{R}^{2}=.140\left(p<.001^{* *}\right)$ & & & & \\
Parent Gender & & & & \\
Custodial Parent & 4.059 & 2.047 & .098 & $.048^{*}$ \\
Parent Ethnicity & 3.248 & 2.216 & .072 & .143 \\
Family Size & 2.246 & 1.343 & .081 & .095 \\
Core Family Leisure & -.063 & .410 & -.007 & .878 \\
Balance Family Leisure & .156 & .033 & .251 & $<.001^{* *}$ \\
& .092 & .024 & .204 & $<.001^{* *}$ \\
& & & & \\
\hline
\end{tabular}

Note. ${ }^{*} p<.05 ; * * p<.01 ; \mathrm{n}=378$. A Bonferroni adjustment was used for multiple tests.

A family-wise .05 significance level was used overall, but the Bonferonni adjustment of .01 (or less) significance level was used for individual tests. 
Family Leisure in Single-Parent Families 55

Table 7

Summary of Blocked Regression Equations Predicting Family Adaptability: Parent Data

\begin{tabular}{|c|c|c|c|c|}
\hline Predictor & B & SE B & $\boldsymbol{\beta}$ & $p$ \\
\hline \multicolumn{5}{|c|}{ Block $1 \mathrm{R}^{2}=.018(p=.144)$} \\
\hline Parent Gender & .780 & 1.582 & .026 & .622 \\
\hline Custodial Parent & 3.822 & 1.712 & .118 & $.026^{*}$ \\
\hline Parent Ethnicity & .780 & 1.030 & .039 & .449 \\
\hline Family Size & .281 & .315 & .047 & .372 \\
\hline \multicolumn{5}{|c|}{ Block $2 \Delta \mathrm{R}^{2}=.135\left(p<.001^{* *}\right)$} \\
\hline Parent Gender & 1.846 & 1.481 & .062 & .213 \\
\hline Custodial Parent & 2.632 & 1.603 & .082 & .101 \\
\hline Parent Ethnicity & .558 & .972 & .028 & .566 \\
\hline Family Size & -.050 & .297 & .008 & .866 \\
\hline Core Family Leisure & .117 & .024 & .261 & $<.001 * *$ \\
\hline Balance Family Leisure & .059 & .017 & .183 & $.001 * *$ \\
\hline
\end{tabular}

Note. ${ }^{*} p<.05 ;{ }^{* *} p<.01 ; \mathrm{n}=378$. A Bonferroni adjustment was used for multiple tests.

A family-wise .05 significance level was used overall, but the Bonferonni adjustment of

.01 (or less) significance level was used for individual tests. 
56 Family Leisure in Single-Parent Families

Table 8

Summary of Blocked Regression Equations Predicting Family Functioning: Parent Data

\begin{tabular}{lllll}
\hline Predictor & B & SE B & $\boldsymbol{\beta}$ & $\boldsymbol{p}$ \\
\hline & & & & \\
Block $1 \mathrm{R}^{2}=.025\left(p=.049^{*}\right)$ & & & & \\
& & & & \\
Parent Gender & .430 & .340 & .067 & .207 \\
Custodial Parent & .803 & .368 & .116 & $.030^{*}$ \\
Parent Ethnicity & .294 & .221 & .069 & .185 \\
Family Size & .049 & .068 & .037 & .472 \\
& & & & \\
Block 2 $\Delta \mathrm{R}^{2}=.162\left(p<.001^{* *}\right)$ & & & & \\
& & & & \\
Parent Gender & .681 & .313 & .106 & $.030^{*}$ \\
Custodial Parent & .523 & .339 & .075 & .123 \\
Parent Ethnicity & .242 & .205 & .057 & .239 \\
Family Size & -.029 & .063 & -.023 & .638 \\
Core Family Leisure & .028 & .005 & $.286<.001 * *$ \\
Balance Family Leisure & -.014 & .004 & $.199<.001 * *$ \\
\hline
\end{tabular}

Note. ${ }^{*} p<.05 ;{ }^{* *} p<.01 ; \mathrm{n}=378$. A Bonferroni adjustment was used for multiple tests.

A family-wise .05 significance level was used overall, but the Bonferonni adjustment of .01 (or less) significance level was used for individual tests. 
Family Leisure in Single-Parent Families 57

Table 9

Summary of Blocked Regression Equations Predicting Family Cohesion: Youth Data

\begin{tabular}{|c|c|c|c|c|}
\hline Predictor & B & SE B & $\boldsymbol{\beta}$ & $p$ \\
\hline \multicolumn{5}{|c|}{ Block $1 \mathrm{R}^{2}=.029(p=.057)$} \\
\hline Custodial Parent & 4.481 & 2.430 & .098 & .066 \\
\hline Family Size & .042 & .451 & .005 & .926 \\
\hline Youth Gender & 1.797 & 1.136 & .082 & .114 \\
\hline Youth Age & -.594 & .386 & -.081 & .125 \\
\hline Annual Income & .378 & .237 & .085 & .111 \\
\hline \multicolumn{5}{|c|}{ Block $2 \Delta \mathrm{R}^{2}=.130\left(p<.001^{* *}\right)$} \\
\hline Custodial Parent & 2.064 & 2.292 & .045 & .368 \\
\hline Family Size & -.291 & .424 & -.034 & .493 \\
\hline Youth Gender & 1.358 & 1.061 & .062 & .202 \\
\hline Youth Age & -.286 & .370 & -.039 & .440 \\
\hline Annual Income & .154 & .227 & .034 & .499 \\
\hline Core Family leisure & .168 & .036 & .259 & $.001 * *$ \\
\hline Balance Family Leisure & .072 & .023 & .178 & $.002 * *$ \\
\hline
\end{tabular}

Note. ${ }^{*} p<.05 ;{ }^{*} p<.01 ; \mathrm{n}=363$. A Bonferroni adjustment was used for multiple tests.

A family-wise .05 significance level was used overall, but the Bonferonni adjustment of .01 (or less) significance level was used for individual tests. 
58 Family Leisure in Single-Parent Families

Table 10

Summary of Blocked Regression Equations Predicting Family Adaptability: Youth Data

\begin{tabular}{lrrrr}
\hline & & & & \\
Predictor & B & SE B & $\boldsymbol{\beta}$ & $\boldsymbol{p}$ \\
\hline & & & & \\
Block $1 \mathrm{R}^{2}=.028(p=.074)$ & & & & \\
& & & & \\
Custodial Parent & 3.749 & 1.915 & .104 & .051 \\
Family Size & .508 & .355 & .075 & .153 \\
Youth Gender & 1.469 & .895 & .086 & .101 \\
Youth Age & .236 & .304 & .041 & .438 \\
Annual Income & .289 & .187 & .082 & .123 \\
& & & & \\
Block 2 $\Delta \mathrm{R}^{2}=.092\left(p<.001^{* *}\right)$ & & & & \\
& & & & \\
Custodial Parent & 2.179 & 1.847 & .061 & .239 \\
Family Size & .273 & .342 & .040 & .426 \\
Youth Gender & 1.183 & .855 & .069 & .168 \\
Youth Age & .476 & .298 & .082 & .111 \\
Annual Income & .165 & .183 & .047 & .370 \\
Core Family Leisure & .126 & .029 & .246 & $<.001 * *$ \\
Balance Family Leisure & .036 & .018 & .114 & $.047 *$ \\
& & & & \\
\hline
\end{tabular}

Note. ${ }^{*} p<.05 ;{ }^{*} p<.01 ; \mathrm{n}=363$. A Bonferroni adjustment was used for multiple tests. A familywise .05 significance level was used overall, but the Bonferonni adjustment of .01 (or less) significance level was used for individual tests. 
Family Leisure in Single-Parent Families 59

Table 11

Summary of Blocked Regression Equations Predicting Family Functioning: Youth Data

\begin{tabular}{lcccc}
\hline & & & & \\
Predictor & B & SE B & $\boldsymbol{\beta}$ & $\boldsymbol{p}$ \\
\hline & & & & \\
Block $1 \mathrm{R}^{2}=.027(p=.076)$ & & & & \\
& & & & \\
Custodial Parent & .802 & .381 & .112 & $.036^{*}$ \\
Family Size & .025 & .071 & .019 & .720 \\
Youth Gender & .320 & .178 & .094 & .073 \\
Youth Age & -.032 & .061 & -.028 & .595 \\
Annual Income & .061 & .037 & .087 & .103 \\
& & & & \\
Block 2 $\Delta \mathrm{R}^{2}=.146\left(p<.001^{* *}\right)$ & & & & \\
& & & .056 & .259 \\
Custodial Parent & .402 & .355 & .023 & .639 \\
Family Size & -.031 & .066 & .073 & .134 \\
Youth Gender & .247 & .165 & .018 & .712 \\
Youth Age & .021 & .057 & .036 & .481 \\
Annual Income & .025 & .035 & .284 & $<.001 * *$ \\
Core Family Leisure & .029 & .006 & .178 & $.001 * *$ \\
Balance Family Leisure & .011 & .003 & & \\
\hline
\end{tabular}

Note. ${ }^{*} p<.05 ; * p<.01 ; \mathrm{n}=363$. A Bonferroni adjustment was used for multiple tests. A familywise .05 significance level was used overall, but the Bonferonni adjustment of .01 (or less) significance level was used for individual tests. 
60 Family Leisure in Single-Parent Families

Table 12

Summary of Blocked Regression Equations Predicting Family Cohesion: Family Data

(Parent and Youth)

\begin{tabular}{lcccc}
\hline & & & & \\
Predictor & B & SE B & $\boldsymbol{\beta}$ & $\boldsymbol{p}$ \\
\hline & & & & \\
Block $1 \mathrm{R}^{2}=.035\left(p=.005^{*}\right)$ & & & & \\
Custodial Parent & & & & \\
Youth Gender & 5.565 & 2.208 & .132 & $.012^{*}$ \\
Annual Income & 2.468 & 1.036 & .123 & $.018^{*}$ \\
& .336 & .215 & .082 & .120 \\
Block 2 $\Delta \mathrm{R}^{2}=.150\left(p<.001^{* *}\right)$ & & & & \\
Custodial Parent & & & & \\
Youth Gender & 3.506 & 2.052 & .083 & .088 \\
Annual Income & 1.636 & .960 & .082 & .089 \\
Core Family Leisure & .110 & .205 & .027 & .591 \\
Balance Family Leisure & .185 & .033 & .295 & $<.001^{* *}$ \\
& .070 & .023 & .164 & $.003^{* *}$ \\
\hline
\end{tabular}

Note. ${ }^{*} p<.05 ;{ }^{* *} p<.01 ; \mathrm{n}=365$. A Bonferroni adjustment was used for multiple tests.

A family-wise .05 significance level was used overall, but the Bonferonni adjustment of .01 (or less) significance level was used for individual tests. 
Family Leisure in Single-Parent Families 61

Table 13

Summary of Blocked Regression Equations Predicting Family Adaptability: Family Data

(Parent and Youth)

Predictor

B

SE B

阝 p

Block $1 \mathrm{R}^{2}=.028\left(p=.015^{*}\right)$

Custodial Parent

Youth Gender

Annual Income

Block $2 \Delta \mathrm{R}^{2}=.121\left(p<.001^{* *}\right)$

Custodial Parent

Youth Gender

Annual Income

Core family leisure

Balance family leisure
3.909

1.362

.272

2.598

.813

.145

.135

.034
1.631

.765

.159

$.126 .017 *$

$.092 \quad .076$

$.090 \quad .088$

Note. ${ }^{*} p<.05 ; * * p<.01 ; \mathrm{n}=365$ A Bonferroni adjustment was used for multiple tests. A family-wise .05 significance level was used overall, but the Bonferonni adjustment of .01 (or less) significance level was used for individual tests. 
62 Family Leisure in Single-Parent Families

Table 14

Summary of Blocked Regression Equations Predicting Family Functioning: Family Data

(Parent and Youth)

\begin{tabular}{llllc}
\hline Predictor & B & SE B & $\boldsymbol{\beta}$ & $\boldsymbol{p}$ \\
\hline & & & & \\
Block $1 \mathrm{R}^{2}=.038\left(p=.003^{* *}\right)$ & & & & \\
Custodial Parent & .920 & .342 & .141 & $.007^{* *}$ \\
Youth Gender & .377 & .160 & .121 & $.019^{*}$ \\
Annual Income & .057 & .033 & .090 & .086 \\
& & & & \\
Block 2 $\Delta \mathrm{R}^{2}=.162\left(p<.001^{* *}\right)$ & & & & \\
Custodial Parent & .593 & .315 & .091 & .061 \\
Youth Gender & .243 & .147 & .078 & .100 \\
Annual Income & .024 & .031 & .037 & .453 \\
Core family leisure & .031 & .005 & .321 & $<.001^{* *}$ \\
Balance family leisure & .010 & .004 & .150 & $.006^{* *}$ \\
& & & & \\
\hline
\end{tabular}

Note. ${ }^{*} p<.05 ;{ }^{* *} p<.01 ; \mathrm{n}=365$. A Bonferroni adjustment was used for multiple tests.

A family-wise .05 significance level was used overall, but the Bonferonni adjustment of .01 (or less) significance level was used for individual tests. 
Family Leisure in Single-Parent Families 63

\section{Core \& Balance Model of Family Leisure Functioning}

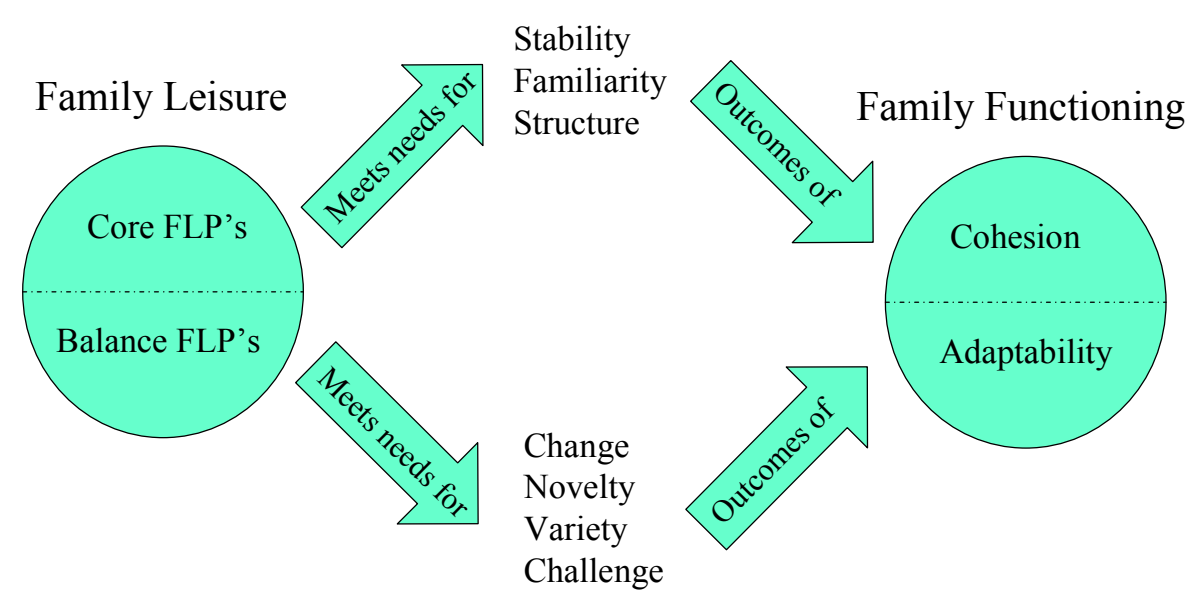

Figure 1. Core and Balance Model of Family Leisure Functioning 
Appendix A

Prospectus 


\section{Chapter 1}

\section{Introduction}

It has been said regarding families that the whole is greater than the sum of its parts. This is clear when the family is understood as a whole system functioning together, and not individual parts working independently side by side. The family systems theory suggests that families are goal oriented, dynamic, self-correcting, and are affected by and affect their environment (Klein and White, 1996). Olsen's (1993) Circumplex Model of Marital and Family Systems was developed to describe the family systems framework, which incorporates varying levels of cohesion and adaptability to describe the functioning family. The functioning family is usually balanced in cohesion across the life cycle. They are not on either extreme side, but have a healthy amount of both connectedness and separateness (Olson, 1993). The functioning family is balanced on adaptability as well. They are able to manage change and stability, avoiding the extreme low and high levels of adaptability for long periods of time. There are different means which may help families obtain optimal levels of family functioning, one being family leisure involvement.

Researchers have found a positive relationship between family functioning and family leisure involvement (Freeman \& Zabriskie, 2003; Zabriskie \& Freeman, 2004; Zabriskie, 2000; Zabriskie \& McCormick, 2003, 2001). Zabriskie and McCormick categorized family leisure into two main groups; core and balance family leisure patterns. Core family leisure most often occurs at home, is spontaneous, and is low in preparation time and financial expenditures; it occurs frequently and can be very simple. Balance 
family leisure is generally less spontaneous and may require extensive planning, time, and money. It occurs less frequently and typically takes place away from home. It is more challenging and is not commonplace in the life of family members. When both types of activities occur in a family, the family experiences higher family functioning (Freeman \& Zabriskie, 2003; Zabriskie \& Freeman, 2004; Zabriskie, 2000; Zabriskie \& McCormick, 2003, 2001). Such family leisure involvement helps fulfill the needs of both stability and change within the family system (Zabriskie \& McCormick).

A family's ability to successfully function as a system is indicated through its ability to cope with change, or in other words its adaptability, and its emotional bonds or feeling of togetherness, which is understood as cohesion. Olson (2000) defines these two concepts in the Complex Model of Marital and Family Functioning. These concepts are facilitated through involvement in family leisure (Zabriskie \& Freeman, 2004). The core family leisure activities help satisfy the need for togetherness and cohesion by allowing time spent together to be predictable in nature and enjoyable, thus promoting closeness and personal relatedness among family members. The balance family leisure activities provide new and exciting challenges to help family members grow and develop as a functioning unit. They provide new experiences of novelty and change, tools that help the family system to function (Zabriskie \& McCormick, 2001).

Researchers indicate that the Core and Balance Model of Family Leisure Functioning correctly predicts a positive relationship between family leisure patterns of core and balance, and successful family functioning including cohesion and adaptability (Zabriskie \& McCormick, 2001). This has been found in many studies with different 
family types; however, little is known regarding single-parent families and the relationship between their family leisure patterns and their family functioning. The Core and Balance Model of Family Leisure Functioning predicts that if single-parent families have low levels of cohesion and adaptability, which they often do, they will also have low levels of family leisure involvement.

\section{Statement of the Problem}

The problem of the study is to examine the contribution of family leisure involvement to family functioning among single-parent families.

A second problem of this study is to examine the difference in family functioning and family leisure involvement between single-parent families and dual-parent families. Purpose of the Study

Little is known about the contribution of family leisure involvement to family functioning among single-parent families; therefore, the purpose of this study is to gain further understanding of this relationship. Such information may provide insight and direction for researchers and practitioners when attempting to strengthen single-parent families and improve their family functioning.

\section{Significance of the Study}

In society the number of single-parent families is growing rapidly (Garanzini, 1995). Single-parent families have a unique and complex set of problems and challenges due to their specific make-up and "tenuous status in society” (Greif, 1996, p. 19). Children of such families are at greater risk to become involved in drugs (Slesnik, Vasquez, \& Bittinger, 2002; Weitoft, Hjern, Haglund, \& Rosen, 2003) and to develop 
anxiety disorders, than those of dual-parent families (Southam-Gerow, Weisz, \& Kendall, 2003). These children are also faced with challenges of poor health and low socioeconomic circumstances (Weitoft et al., 2003). Due to these difficulties, among others, single-parent families may struggle in the areas of family cohesiveness and adaptability, which Olsen (1986) defines as "characteristics of highly functioning families” (p. 339).

A positive relationship has been found between family leisure involvement and successful family functioning in several studies over the years (Hawks, 1991). Previous known-group studies, including families with adopted children (Freeman \& Zabriskie, 2003), and families with a child with a disability (Mactavish \& Schleien, 1998;

Mactavish \& Schleien, 2004; Scholl, McAvoy, Rynders, \& Smith, 2003) have found a positive influence of family leisure on family functioning. Researchers have expressed the need for further studies on non-traditional families (Holman \& Epperson, 1984; Zabriskie \& McCormick, 2003), and specifically for a "[broad] national sample of singleparent families [with data collected] from multiple sources, including parents and children within the home” (Smith, Taylor, Hill, \& Zabriskie, 2004, p. 53). If a positive relationship is also found in the known group study of single-parent families among these aspects of family life, findings will have significant implications for single-parent families and all associated with them.

The information gained from this study may provide a foundation for further understanding of family leisure involvement and family functioning among single-parent families, which would be helpful in strengthening and improving the functioning of these 
families. “Although shared leisure activities are not a panacea for all family problems, family leisure affects the quality of life and may be particularly helpful in facilitating family cohesion and adaptability” among this population (Zabriskie \& McCormick, 2001, p. 287). By studying the family functioning and family leisure involvement of singleparent families, specific information may be found that is helpful for the members of these families. This information could in turn influence state and federal family services, the development of leisure education programs, and other community based programs that provide services for single-parent families.

\section{Delimitations}

The scope of the study will be delimited to the following:

1. The study will include 400 nationwide single parents with at least one child who is 11 to 15 years.

2. The study will include 400 nationwide dual-parent families with at least one child who is 11 to 15 years.

3. Responses will be collected from one youth between the ages of 11 and 15 and the single parent of each single-parent family.

4. Responses will be collected from one youth between the ages of 11 and 15 and one parent from each dual-parent family.

5. Family leisure patterns will be measured with the Family Leisure Activity Profile (FLAP) (Zabriskie \& McCormick, 2001).

6. Family functioning (cohesion and adaptability) will be measured with the Family Adaptability and Cohesion Evaluation Scales (FACES II) (Olson, 2000). 
7. The data will be collected, starting January 2006, until a sufficient pool is found nationwide (800 families).

\section{Limitations}

The study will be limited by the following factors:

1. The influence of the parent on the child doing the survey cannot be followed.

2. Each survey will be self-reported by paid volunteers who may be influenced by social or financial desires.

3. Because the data will be collected through an online survey, some people may be excluded from participating.

4. Due to the fact that the methods of this study are correlational, causal relationships cannot be determined.

\section{Assumptions}

This study will be conducted based upon the following assumptions:

1. The FACES II instrument (Family Adaptability and Cohesion Scales) will provide a valid and reliable measure of family functioning (Olson, McCubbin, Barnes, Larsen, Muxen, \& Wilson, 1992).

2. The FLAP instrument (Family Leisure Activity Profile) will provide a valid and reliable measure of family leisure involvement (Zabriskie \& McCormick, 2001).

3. Participants will be honest when completing the questionnaire. Hypotheses

The study was designed to test the following null hypotheses: 
1. There is no relationship between family leisure and family functioning among single-parent families.

2. There is no difference between single-parent families and dual-parent families in their family functioning and family leisure involvement.

3. There is no difference between single-parent families and dual-parent families in their family cohesion and adaptability.

4. There is no difference between single-parent families and dual-parent families in their core and balance family leisure patterns.

Definitions of Terms

The following terms are defined to clarify their use in this study:

Balance leisure patterns. Balance patterns provide novel experiences through activities that are often less frequent and common than core activities. A greater investment of time, effort, and money are usually required by these activities than core activities and they are usually not home based. "Balance activities often require substantial planning, and are, therefore, less spontaneous and more formalized. As a result, it would be anticipated that these types of family activities occur less frequently. However, they would tend to be of longer duration than most core activities” (Zabriskie \& McCormick, 2001, pp. 283-284).

Core leisure patterns. “Core family leisure patterns are depicted in the common, everyday, low-cost, relatively accessible, and often home-based activities that many families do frequently. . . Core activities often require little planning and resources, and are quite spontaneous and informal” (Zabriskie \& McCormick, 2001, p. 283). 
Family adaptability. Refers to the family's ability, in response to situational and developmental stress, to change its power structure, role relationships, and relationship rules (Olson, Portner, \& Bell, 1982).

Family cohesion. Refers to the emotional bonding between family members (Olson, Portner, \& Bell, 1982).

Family leisure patterns. Refers to participation in activities together as a family which fall into two main categories (core and balance) as outlined by The Core and Balance Model of Family Leisure Functioning (Zabriskie \& McCormick, 2001). Single-parent family. Refers to a family consisting of only one parent, whether it be a father or mother, and at least one dependent between the ages of 11 and 15 . 


\section{Chapter 2}

\section{Review of Literature}

One problem of the study is to examine the contribution of family leisure involvement to family functioning among single-parent families. A second problem of this study is to examine the difference in family functioning and family leisure involvement between single-parent families and dual-parent families. The following literature review explores (a) family functioning, (b) single-parent families, (c) family leisure, and (d) family leisure and single-parent families.

\section{Family Functioning}

The family is the basic unit of society. To understand how this unit functions and how it can be strengthened is important to each family and to society. Family systems theory is one of the most widely accepted and utilized paradigms for understanding families and family behaviors (Broderick, 1993). This framework suggests that the family unit is greater than the sum of its parts; therefore, viewing the family as a whole is best when seeking to understand its behavior. Each change in an individual will affect every member of the family system, as will a change in the system affect the behaviors of each family member (White \& Klein, 2002). Zabriskie and McCormick (2001) discuss other basic elements of family systems theory quoting Klein and White (1996): the family systems theory "holds that families are goal directed, self-correcting, dynamic, interconnected systems that both affect and are affected by their environment and by qualities within the family system itself” (p. 281). 
Many models have been created to describe the family systems framework, but Olsen’s (1993) Circumplex Model of Marital and Family Systems is used most often. This model was built to bridge the gap often present between research, theory, and practice (Olson, 1993). It focuses on a relations system and “integrates three dimensions that have repeatedly been considered highly relevant in a variety of family theory models and family therapy approaches, namely, family cohesion, [adaptability], and communication. These three dimensions in the Circumplex Model emerged from a conceptual clustering of over 50 concepts developed to describe marital and family dynamics” (Olson, 1993, p. 515). Communication is considered a facilitating dimension and thus is not included graphically in the model with cohesion and adaptability; therefore the focus will remain on the latter two.

Olson (1993) defines family cohesion "as the emotional bonding that couples and family members have toward one another” (p. 516). The level of cohesion is determined by the family system's balance of separateness and togetherness. The unbalanced family system is found either on the extreme low or high level of cohesion.

Olson (1993) defines family adaptability as "the amount of change in its leadership, role relationships, and relationship rules. [Adaptability] concerns how systems balance stability with change” (p. 519). Stability and change are needed by couples and families, and the ability to change when the need arises is a defining characteristic of functional couples and families. The dysfunctional, unbalanced family system is found either on the extreme low or high level of adaptability. 
While being at the extreme low or high level of cohesion or adaptability for long periods of time is often very problematic for a family, there is no absolute best level for any one family (Olson, 1993). There are many different family types and each type has optimal levels of family functioning. Single-parent families are one of the many different family types that must deal with many unique issues that affect their family functioning. Single-Parent Families

Society is experiencing a significant increase in the number of single-parent families, and this growth is predicted to continue in years to come. Single-parent families headed by mothers increased to 10 million in the year 2000, from 3 million in 1970 . Single-parent families headed by fathers increased to 2 million from 393,000 in those same years (Family Discipleship Ministries, 2002). In 1950, nearly 80\% of the children born could expect to be reared in their early years by two parents (Garanzini, 1995).

Conversely, in 1995 almost 50\% of the children born were expected to spend at least some of their early years in a single-parent family (Garanzini, 1995). In 1986, the status of single-parent families, headed by mothers, was about $88 \%$ with the remaining $12 \%$ headed by fathers. About $7 \%$ were a result of the death of a parent, while the majority were a result of divorce. Nearly one in four children (24\%) was living with their mother who never married (Garfinkle \& McLanahan, 1986). According to Garanzini (1995), this type of single-parent family, where marriage has never occurred, is the “fastest growing family type” of single-parent families (p. 95).

Single-parent families often experience lower family functioning than dual-parent families (Garanzini, 1995; Greif, 1996; Moore \& Vandivere, 2000). A variety of “severe 
and complex difficulties” often accompany single-parent families and their "tenuous status in society” (Greif, 1996, p. 19). These difficulties are dependant on their family structure, whether they are headed by a father or a mother, and whether the single-parent status is a result of the parent never-marrying, divorce, death, or military service (Greif, 1996).

Single mothers face financial difficulties resulting from the dual role they must fill to care and provide for their children; their meager child support, if they receive such; and their usually low income (Garfinkle \& McLanahan, 1986). In the United States, the poverty rate of female-headed households is six times greater than that of other families (U.S. Bureau of the Census, 1992). On the other hand, single fathers are usually better educated and are more likely to have stable, higher paying jobs, thus enabling them to maintain a higher standard of living (Garanzini, 1995; Hoffman \& Duncan, 1988). "Fathers are able to gain compliance from their children more than are single mothers," but they feel more insecure than mothers about caring for their children's emotional needs (Garanzini, 1995, p. 95). Various struggles accompany single-parent families, depending on their reason for being a single-parent family.

When the death of a spouse occurs, the family needs a warm, supportive atmosphere in order to grieve and heal. This atmosphere is created by family, friends, and society (Garanzini, 1995). Children are given the necessary permission to grieve the loss of their parent, no matter the length of time required. This is not usually the case when the status of a single-parent family results from a divorce. The knowledge of the separation and divorce is usually kept private. With the complications of divorce, it is 
potentially more stressful on the parent and children than the death of a spouse/parent (Garanzini,1995). The resulting pressures and struggles that fall upon single-parent families, regardless of the cause of their "singlehood," whether it be through death, divorce, or other means, can cause immense stress on them and their successful functioning (Garanzini,1995). Single-parent families are more than twice as likely to have stressful family environments than dual-parent families (Moore \& Vandivere, 2000). Such stresses include poor health and inability to meet essential household expenses, such as food, shelter, and adequate health care. Children living in stressful family environments (one in five in the United States) are likely to exhibit high levels of emotional and behavioral problems by almost four times as much, and are almost two times more likely to under perform in school than those children living in non-stressful family environments (Moore \& Vandivere, 2000).

The parent-child relationship can often be under duress in single-parent families, resulting in unhealthy adaptations. Depression and low self-esteem are common feelings single parents must deal with, and these feelings have a negative effect on their relationship with family functioning and family processes (Brody \& Flor, 1997; Garanzini, 1995). The parent, under much turmoil and stress, may inadvertently turn inward in an attempt to heal from his or her own pain and suffering, becoming insensitive to their child's ever pressing emotional and physical needs. The child may then act out, seeking attention for his or her unmet developmental needs (Garanzini, 1995; Wallerstein, Lewis, \& Blakeslee, 2000). This lack of adaptability has a negative effect on the cohesion of the family. 
Two problems for single-parents discussed by Cooney and Mortimer (1999) are household chores and a lack of parental supervision in single-parent families. A common source of contention among most parents and teenagers nationwide is the requirement of "help around the house" by the parents. However, twice as much help is often required from the children of single-parent families than those of dual-parent families (Cooney \& Mortimer, 1999). The double amount of housework required at the hands of the singleparent can be a great source of contention, keeping family cohesion and family closeness at bay.

The second problem discussed by Cooney and Mortimer (1999) is that single parents are also believed to monitor their teenagers’ activities less closely than dualparents, which results in “undesirable, age-inappropriate behaviors” (p. 373) of the teenagers. This lack of parental monitoring is believed to create a deep peer orientation in teenagers, much more so than in those teenagers who are monitored closely by their parents. This naturally results in a lack of family cohesion and closeness because the teenagers are much more interested in their friends than in their families.

Another common problem in single-parent families occurs when the parent uses his or her child as a substitute for the missing spouse. This forces the child into an unnatural adult role, that of emotionally caring for the parent, and becoming the parent's confidant (Garanzini, 1995; Greif, 1996). The child may even place him or herself in this role in an attempt to compensate for the overwhelming feelings of loss for the other parent, or to ease the sense of being a burden for the single-parent (Garanzini, 1995). 
Again, these issues result in negative family functioning, which is often present in singleparent families.

Several studies have reported a positive influence of family leisure involvement on family functioning among families with different family structures, including specialneeds adoptive families and families with a child who has a disability (Freeman \& Zabriskie, 2003; Mactavish, \& Schleien, 1998; Mactavish, \& Schleien, 2004; Scholl, McAvoy, Rynders, \& Smith, 2003). Little is known, however, about family leisure among single-parent families. Recent studies suggest that there may be a strong relationship between family leisure and family functioning among single-parent families. (Smith, et al., 2004; Taylor, Zabriskie, Smith, \& Hill, 2004).

Family Leisure

The study of family leisure has evolved over the past 70 years with a consistent positive relationship found between successful family functioning and family leisure (quality time spent together in leisure pursuits as a family) (Hawks, 1991). Taylor (2005) discusses the course of family leisure research throughout these decades. Beginning in the 1930s researchers began to focus on the way leisure time was spent by Americans. In the decades that followed, studies on a variety of leisure topics were performed, including children’s leisure and married couples' leisure interests. The focus eventually shifted to family leisure, which involved marital relationships, parent-child relationships, and the family as a whole.

Mactavish and Schleien (1998) found the benefits of the family leisure involvement to be skill building in certain adaptive areas such as negotiating, 
compromising, and problem solving. Zabriskie (2000) found a positive relationship between family leisure involvement and family functioning when measured from the perspectives of a child, a parent, and the family. Similarly, Scholl, McAvoy, Rynders, and Smith (2003) found an increase in family cohesion and satisfaction among families who have a child with a disability when participating in outdoor recreation as a family. In addition, Huff, Widmer, McCoy, and Hill (2003) found a reduction in conflict among families who participated in challenging outdoor recreation, due to an increased willingness to work together through disagreements and problems. This stemmed from the increase in trust, support, kindness, affection, interaction, and communication, among other qualities found in families who participated in the outdoor recreation during the study. Wells, Widmer, and McCoy (2004) found an increase in family efficacy among families who participated in challenging activities. The confidence levels of these families increased allowing them to perform tasks together and resolve problems. Although a positive relationship has been well established, there have been several criticisms of the early body of research between family leisure involvement and family functioning. A more clear understanding of this relationship can be brought about by addressing specific issues therein.

Freeman and Zabriskie (2003) state, "the nature of the relationship [between family leisure and aspects of family functioning] is still poorly understood” (p. 75). Zabriskie \& McCormick (2001) discuss some weaknesses in early research of family leisure which, when addressed, may help clarify the positive relationship between family leisure and family functioning. A majority of early family leisure research examines the 
relationship among married couples only, and infers findings to the broader family system. Another concern in family leisure research involves leisure being typically “operationalized in a simplistic and inconsistent manner. Measurement has included any time spent together, as well as lists of activities placed into categories with no theoretical basis” (p. 283). This historical lack of an adequate theoretic framework has limited findings to the "idiosyncrasies of the investigation at hand" (Orthner \& Mancini, 1991, p. 299). Many scholars have recognized this concern, calling for theory based family leisure research (Hawks, 1991; Holman, \& Epperson, 1989; Orthner \& Mancini, 1990). "It is imperative to identify and test theoretical models of family leisure that could provide the basis for strengthening measurement, generating hypotheses, and interpreting results when examining family leisure” (Zabriskie \& McCormick, 2001, p. 283).

The need for a theoretic framework from which to examine family leisure may have been addressed in part by the family systems theoretical perspective, which offered a sound avenue from which to examine the relationship of family and leisure (Orthner \& Mancini, 1991). Zabriskie and McCormick (2001) correlated family leisure and the family systems theory, which suggested that “all three dimensions of Olson’s (1986) Circumplex Model (cohesion, adaptability, and communication)” were directly facilitated through involvement in family leisure (Zabriskie \& Freeman, 2004, p. 54). This instigated the development of a new model used to study the relationship between family leisure and family functioning. The Core and Balance Model of Family Leisure Functioning (Zabriskie, 2000) is grounded in the family systems theory and "suggests 
that there is a direct relationship between” family leisure patterns and family cohesion and adaptability (Zabriskie \& Freeman, 2004, p. 54).

Core and Balance Model of Family Leisure Functioning. To come to an understanding of the meaning and purpose of leisure for the individual, Kelly (1996, 1999) identifies two main types of leisure that most people engage in throughout their life. One type is ongoing, stable, and easily accessible throughout one’s life, while the second is opposite in nature. The second type of leisure adds variety, is less accessible and persistent, and is often changing throughout the course of one's life. Iso-Ahola (1984) indicates that individual behavior is influenced by the human need to create a balance between two opposing forces. He states that individuals have a tendency to “seek both stability and change, structure and variety, and familiarity and novelty in [their] leisure” (p. 98). By participating in leisure activities of security (stability) and novelty (change) individuals fulfill the need for balancing stability and change.

This need for balance between stability and change may even be enhanced when considered in the context of the family unit. In family systems theory, the underlying concept "suggests that families seek a dynamic state of homeostasis. Families as a system have a need for stability in interactions, structure, and relationships, as well as a need for novelty in experience, input, and challenge” (Zabriskie \& McCormick, 2001, p. 283). Families, similar to individuals, seek such a balance through their leisure activities. This phenomenon is explained through the Core and Balance Model of Family Leisure Functioning (Zabriskie \& McCormick, 2001). 
Zabriskie and McCormick’s (2001) Core and Balance Model of Family Leisure Functioning divides leisure patterns families use to achieve stability and change as they seek their dynamic state of homeostasis into two main categories-core and balance. Core family leisure patterns answer the need “for familiarity and stability” by providing a regular dose of family leisure experiences that are predictable in nature and help promote closeness among family members and personal relatedness (p. 283). Balance family leisure patterns, on the other hand, provide avenues for the family to be challenged, and to grow and develop as a functioning unit. These experiences answer the “family's need for novelty and change by providing new experiences” and input for the family system to function (p. 283). In order for the family to have both stability (cohesion) and change (adaptability) it needs both core and balance activities in relatively equal amounts. Such leisure patterns of the family are apparent "when examining the nature of leisure activities engaged in by families as well as the context in which they occur” (p. 283).

Zabriskie and McCormick (2001) describe core family leisure patterns as activities that cost little, may be participated in on a daily basis, are at home, and are ordinary activities that family members engage in often. These activities may include playing games, reading books, playing basketball or soccer at home, or simply playing in the yard. These activities provide an environment where family members can build and deepen relationships in the non-threatening, familiar “at-home” feeling. This play provides release from work and is “just for fun” while consoling, rewarding, refreshing, and rejuvenating those who participate. In addition, because they are considered "just for fun” they may provide a trial-arena for the exploration of family boundaries, roles, and 
rules, where no one is hurt. Core leisure patterns are engaged in a socializing context which provides a means for communication, not only of the common everyday events, but also a more comfortable setting for expressing feelings and emotions of individuals. This results in interpersonal connectivity of family members which in turn builds family closeness and cohesion (Zabriskie \& McCormick, 2001).

Zabriskie and McCormick (2001) describe balance patterns as activities that are less regular, participated in less often, and thus provide unique experiences. More time, effort, and money are often required for these activities and they usually take place away from home. Some examples of balance activities include traveling; vacations; outdoor activities, such as camp-outs; waterskiing; or fishing together as a family. Other balance activities may include miniature golf, attending sports events, or going to fairs or parks. Much planning often goes into balance activities and as a result, they are less spontaneous and occur less often. Nevertheless, they tend to last longer than core activities usually do. These activities are usually accompanied with novelty and unpredictability, thus creating an environment of new input, challenges, and experiences that family members must adapt to and negotiate with, including each other. These activities expose family members to unfamiliar and surprising stimuli from the environment, requiring them to learn and progress as a family unit. The skills acquired are easily transferable to other family-life areas (Zabriskie \& McCormick, 2001).

A positive relationship between family leisure patterns and successful family functioning, involving family cohesion and adaptability, has been empirically reported in several studies using the Core and Balance Model of Family Leisure Functioning 
(Zabriskie \& McCormick, 2001) (i.e., Freeman \& Zabriskie, 2003; Zabriskie, 2000, 2001; Zabriskie \& Freeman, 2004; Zabriskie \& McCormick, 2001, 2003). More specifically, family cohesion is affected more by core leisure activities, while family adaptability is influenced by both balance and core activities. Balance patterns influence family adaptability of families who are either extremely high or extremely low functioning (Zabriskie \& Freeman, 2004; Zabriskie \& McCormick, 2001). Interestingly, the youth in most studies of core/balance family leisure patterns place more value on core family leisure patterns than balance family leisure patterns. However, both core and balance family leisure patterns are of equal importance to the parents and the family as a whole. (Freeman \& Zabriskie, 2003; Zabriskie \& Freeman, 2004; Zabriskie \& McCormick, 2003).

During the past five years, significant research has been completed on family leisure and family functioning utilizing the Core and Balance Model of Family Leisure Functioning (Zabriskie \& McCormick, 2001). Some of these studies have examined traditional families and have collected data from a young adult perspective, as well as a child, parent, and family perspective (Zabriskie, 2000; Zabriskie \& McCormick, 2001, 2003). There has also been a variety of known-group studies that have utilized the Core and Balance Model to examine different types of families with known characteristics. Some of these include families with special needs adoptive children (Zabriskie \& Freeman, 2004), families with youth in mental health treatment, and Hispanic families (Christenson, Zabriskie, Eggett, \& Freeman, in press). Each of these known-group studies 
has provided further support for the Core and Balance Model and its use for examining family leisure.

Zabriskie and McCormick (2001) suggest that today family leisure is quite possibly one of the rare experiences in which families spend a sufficient amount of time together, aside from a family crisis. Researchers have consistently found a positive correlation between successful family functioning and family leisure patterns. Zabriskie and Freeman (2004) found that "when considering other family characteristics such as race, family size, religion, history of divorce, and annual family income, the only significant predictor of higher family functioning was family leisure involvement” (p. 70). This body of research supports the claim that in today's society family leisure is one of the most important elements in building cohesive relationships in families (Couchmanm 1988, as cited in Canadian Parks/Recreation Association, 1997). Very few studies, however, have examined family leisure involvement among single-parent families.

\section{Family Leisure and Single-Parent Families}

Based on the literature discussed previously, single-parent families are, for the most part, lower functioning than dual-parent families. The Core and Balance Model of Family Leisure Functioning suggests that if a family is lower functioning they will also have less family leisure involvement than dual-parent families. Although previous known-group studies, including families with adopted children (Freeman \& Zabriskie, 2003), and families with a child who has a disability (Mactavish, \& Schleien, 1998; Mactavish, \& Schleien, 2004; Scholl, McAvoy, Rynders, \& Smith, 2003) have found a 
positive influence of family leisure on family functioning, researchers have expressed the need for further studies on non-traditional families (Holman \& Epperson, 1984; Zabriskie \& McCormick, 2003), and specifically for a “[broad] national sample of single-parent families [with data collected] from multiple sources, including parents and children within the home” (Smith et al., 2004, p. 53). A pilot study which consists of a convenience sample of 46 college students who had grown up for at least 2 years in a single-parent home found that "when compared to dual-parent families, the single-parent sample demonstrated lower levels of family functioning and less participation in family leisure. However, single-parent families participated in considerably less balance leisure, but not significantly less core leisure than dual-parent families . . . [These noteworthy findings] indicate a relatively strong relationship between family leisure involvement and family functioning among those in a single-parent family structure” (Smith et al., 2004, p. 53).

While findings for this initial study add considerable insight into family leisure among single-parent families, there were several limitations. The sample was relatively small and homogenous in nature. The sample consisted of college students who responded based on memory of being raised in a single-parent family. Authors recommend that data be gathered from a broader, more representative sample of singleparent families, and from multiple perspectives of those living in the home.

\section{Summary}

There are many different family types and each type has optimal levels of family functioning. The family systems theory is used in Olsen’s (1993) Circumplex Model of 
Marital and Family Systems to understand family functioning in terms of varying levels of cohesion and adaptability. Single-parent families deal with many complex issues that often lower their family functioning in the areas of cohesion and adaptability.

The Core and Balance Model of Family Leisure Functioning is used to understand the leisure patterns families utilize to achieve stability (core) and change (balance) as they seek family cohesion and adaptability. A positive relationship between a functional family and its family leisure patterns has consistently been demonstrated in family leisure examinations. This positive relationship between family leisure involvement and family functioning has been found when measured from the perspectives of a child, a parent, and the family.

The Core and Balance Model of Family Leisure Functioning predicts that if single-parent families have low levels of cohesion and adaptability they will also have low levels of family leisure involvement when compared with dual-parent families. A positive relationship has been established between family leisure and family functioning among several known-group studies. There is very little research though, if any, on the family leisure patterns of single-parent families. Researchers have called for further study on the relationship of single-parent families, their family functioning, and their patterns of family leisure.

Furthering the research on the Core and Balance Model of Family Leisure Functioning model will significantly impact those who work with families as well as the individuals in the families themselves. It will also establish a new foundation for future lines of family leisure study, and influence most social sciences that address families. It is 
anticipated that findings will have significant implications for single-parent families, professionals, services, and agencies that work with such families, and may provide direction for pro-active intervention strategies. Therefore, the purpose of this study is to examine the contribution of family leisure involvement to the family functioning of single-parent families among a large national representative sample. 


\section{Chapter 3}

\section{Methods}

The problem of the study is to examine the contribution of family leisure involvement to family functioning in a national sample of single-parent families. A second problem of this study is to examine the difference in family functioning and family leisure involvement between national samples of single-parent families and dualparent families. Included in this chapter are the following: (a) sample, (b) instrumentation, (c) data collection procedures, and (d) analysis. Sample

The sample for this study will be a nationally representative sample collected in cooperation with Survey Sampling International. It will include 400 dual-parent families and 400 single-parent families that will consist of one parent, either a father or mother, and one dependent child 11 to 15 years of age. The restricted age range will be implemented to involve children at a cognitive development level with the ability to use abstract thinking necessary for understanding and completing the survey instrument. Psychosocially, children at this age still need the security of parents and family members, but are beginning to separate themselves from their parents and find their own identity (Zabriskie \& McCormick, 2003). As Zabriskie and Freeman (2004) point out, "scholars have called studies for special needs adoptive family systems to go beyond a parent only perspective and examine a child's perspective of family functioning as well” (p. 57). In order to gather family members' perspectives of their functioning, this study will collect 
data from a dependent child as well as the parent. This will provide two perspectives from each family on their family functioning and leisure.

\section{Instrumentation}

The questionnaire will include three sections: (a) Family Adaptability and Cohesion Scales (FACES II), which provides a measure of the family's perception of their family cohesion, family adaptability, and overall indicators of family functioning (Olson, McCubbin, Barnes, Larsen, Muxen, \& Wilson, 1992), (b) Family Leisure Activity Profile (FLAP), which provides a measure of core, balance, and overall family leisure involvement (Zabriskie \& McCormick, 2001), and (c) relevant sociodemographic questions.

FACES II. The Family Adaptability and Cohesion Scales includes 30 items used to measure individual perceptions of family cohesion and adaptability. It is also used to calculate family functioning based on Olson’s Circumplex Model (Olson, 1986). There are 14 questions that contribute to family adaptability. The other 16 questions refer to family cohesion (Olson et al., 1982). The answers are given on a one to five-point Likert scale with one being “almost never” and five being "almost always.” Scores for family cohesion and family adaptability are calculated based on a scoring formula that accounts for reverse coded questions. After obtaining total cohesion and total adaptability scores, corresponding 1 - 8 values will be assigned based on the linear scoring interpretation of Olson et al. (1992). These two scores will be averaged in order to obtain the family type score which is used as an indicator of overall family functioning. The FACES II scale has 
acceptable evidence of validity and reliability. Cronbach Alpha coefficients are reported as .78 and .79 for adaptability and .86 and .88 for cohesion (Olson et al., 1992).

FLAP. The Family Leisure Activity Profile measures core and balance family leisure involvement based on the Core and Balance Model of Family Leisure Functioning (Zabriskie, 2000). Eight questions refer to core leisure activities in which family members participate (usually home-based family activities) and eight refer to balance activities in which family members participate (tourism, adventure activities, etc.). In each question, the respondent will be given examples of activities. The respondent will then be asked if he or she participates in those activities with other family members, and if so, how often and for how long. They also indicate on a five-point Likert scale their satisfaction with these family activities ( 1 = very dissatisfied and 5 = very satisfied).

An index score is found for each question by multiplying duration and frequency. The core index score is found by summing the index scores of questions 1-8, and the balance index score is calculated by summing the index scores of questions 9-16. The total family leisure score is calculated by summing the core and balance index scores. (Zabriskie \& McCormick, 2001). Acceptable psychometric properties are demonstrated for the FLAP scale with evidence of construct validity, content validity, inter-rater reliability, and test-retest reliability for core $(r=.74)$, balance $(r=.78)$, and total family leisure involvement $(r=.78)$ (Zabriskie, 2001).

Demographics. A series of sociodemographic questions will be included to identify underlying characteristics of the sample. These items will include age, gender, ethnicity, religion, state of residence, population of place residing (urban or rural), annual 
family income, family size, relationship of parents to all children (i.e., biological, stepparent, adoptive parent), children's ages, length of time as a single-parent family, reason for single-parent status (divorce, widow, separated, never married, other), and percent of time child/children spend with custodial parent.

\section{Data Collection Procedures}

An online questionnaire will be used to collect the data beginning second or third week of January 2006 and continue until an adequate sample is gathered. The participants will be expected to complete the questionnaire on their own after receiving the internet location. At the beginning of the questionnaire, participants will read that by completing the questionnaire they will be consenting to participate. They will also be told that their participation is voluntary, and thus, they can stop at any time. Confidentiality of the participants will be ensured because no questions will ask for personal identification on the questionnaire, though demographic questions will be asked. The data will be stored on a database and exported to an Excel file that will be protected by a password. Analysis

The statistical package SAS will be used to analyze the data. Data will be reviewed for missing responses and outliers. Three data sets will be compiled: (a) responses of parents, (b) responses of dependent children, and (c) family level measurement (the mean for each family). Underlying characteristics of the research variables will be examined with descriptive statistics. Pearson Product Moment zeroorder correlations between variables in each of the three data sets will be examined for multicollinearity as well as to identify possible controlling factors that could be included 
in subsequent multiple regression equations. Sociodemographic variables, which indicate zero-order correlation coefficients with the dependent variables, will be included in the multiple regression models to examine the unique contributions of family leisure involvement to family functioning. Three multiple regression analyses will examine the contributions to family leisure involvement from a perspective of the parent, the youth, and the family. The block method will be used in each analysis. The multiple regression coefficients will be examined for each model at a .05 alpha level. The relative contribution of each variable in significant models will be determined with standardized regression coefficients (Beta).

To examine the difference in family functioning and family leisure involvement between single-parent families and dual-parent families the three data sets will be used: (a) responses of parents, (b) responses of dependents, and (c) family level measurement (the mean for each family). To test for significant differences between samples, an ANCOVA adjusting for significant demographic variables will be used. 


\section{References}

Broderick, C. B. (1993). Understanding family process: Basics of family systems theory. Thousand Oaks, CA: Sage.

Brody, G. H., \& Flor, D. L. (1997). Maternal psychological functioning, family processes, and child adjustment in rural, single-parent, African American families. Developmental Psychology 33(6), 1000-1012.

Canadian Parks/Recreation Association (1997). The benefits catalogue. Gloucester, Ontario, Canada: Author.

Christenson, O., Zabriskie, R., Eggett, D., \& Freeman, P. (in press). Family acculturation, family leisure involvement, and family functioning among Mexican-Americans. Journal of Leisure Research, 38(4).

Cooney, T. M., \& Mortimer, J. T. (1999). Family structure differences in the timing of leaving home: Exploring mediating factors. Journal of Research on Adolescence, 9(4), 367-394.

Family Discipleship Ministries. (2002.) Alarming Statistics. Retrieved September 19, 2003, from http://www.parentingministry.org/Alarming_Statististis.htm

Freeman, P., \& Zabriskie, R. B. (2003). Leisure and family functioning in adoptive families: Implications for therapeutic recreation. Therapeutic Recreation Journal, 37(1), 73-93.

Garanzini, M. J. (1995). Child-centered, family-sensitive schools: An educator's guide to family dynamics. Washington, DC: National Catholic Educational Association.

Garfinkle, I., \& McLanahan, D. (1986). Single mothers and their children: A new 
American dilemma. Washington, DC: Urban Institute Press.

Greif, G. L. (1996). Treating the changing single-parent family: A return to boundaries. Children Today, 24(1), 19-22.

Hawks, S. R. (1991). Recreation in the family. In S. J. Bahr (Ed.), Family research: A sixty year review, 1930-1990 (pp. 387-433). New York: Lexington Books.

Hoffman, S. D., \& Duncan, G. J., (1988). What are the economic consequences of divorce? Demography, 25(64), 1-45.

Holman, T.B. \& Epperson, A. (1984). Family and leisure: A review of the literature with research recommendations. Journal of Leisure Research, 16, 277-294.

Holman, T. B., \& Epperson, A. (1989). Family and leisure: A review of the literature with research recommendations. Journal of Leisure Research, 16, 277-294.

Huff, C., Widmer, M., McCoy, K., \& Hill, B. (2003). The influence of challenging outdoor recreation on parent-adolescent communication. Therapeutic Recreation Journal, 37(1), 18-37.

Iso-Ahola, S. E. (1984). Social psychological foundations of leisure and resultant implications for leisure counseling. In E. T. Dowd (Ed.), Leisure counseling: Concepts and applications (pp. 97-125). Springfield, IL: Charles C. Thomas.

Klein, D. M., \& White, J. M. (1996). Family theories: An introduction. Thousand Oaks, California: Sage.

Kelly, J. R. (1996). Leisure (3rd ed.). Needham Heights, MA: Allyn \& Bacon.

Kelly, J. R. (1999). Leisure behaviors and styles: Social, economic, and cultural factors. 
In E. L. Jackson \& T. L. Burton (Eds.), Leisure studies: Prospects for the twentyfirst century (pp. 135-150). State College, PA: Venture.

Mactavish, J., \& Schleien, S. (1998). Playing together growing together: Parents' perspectives on the benefits of family recreation in families that include children with a developmental disability. Therapeutic Recreation Journal, 32(3), 207-230.

Mactavish, J., \& Schleien, S. (2004). Re-injecting spontaneity and balance in family life: parents’ perspective on recreation in families that include children with developmental disability. Journal of Intellectual Disability Research 48(2), 123141.

Moore, K. A., \& Vandivere, S. (2000). Stressful family lives: Child and parent wellbeing. New Federalism: National Survey of America's Families (B), B-17.

Olson, D. H. (1986). Circumplex model VII: Validation studies and Faces III. Family Process, 25, 337-351.

Olson, D. H. (1993). Circumplex model of marital and family systems: Assessing family systems. In F. Walsh (Ed.), Normal Family Processes (pp. 104-137). New York: Guilford Press.

Olson, D. H. (2000). Circumplex Model of Marital and Family Systems. Journal of Family Therapy, 22(2), 144-167.

Olson, D. H., McCubbin, H. I., Barnes, H., Larsen, A., Muxen, M., \& Wilson, M. (1992). Family inventories: 2nd Revision. St. Paul, MN: University of Minnesota.

Olson, D. H., Portner, J., and Bell, R. (1982). FACES II: Family adaptability and 
cohesion evaluation scales. St. Paul, MN: Family Social Science, University of Minnesota.

Orthner, D. K., \& Mancini, J. A. (1990). Leisure impacts on family interaction and cohesion. Journal of Leisure Research, 22(2), 125-137.

Orthner, D. K., \& Mancini, J. A. (1991). Benefits of leisure for family bonding. In B. L. Driver, P. J. Brown, \& G. L. Peterson (Eds.), Benefits of leisure (pp. 215-301). State College, PA: Venture.

Scholl, K., McAvoy, L., Rynders, J., \& Smith, J. (2003). The influence of inclusive outdoor recreation experience on families that have a child with a disability. Therapeutic Recreation Journal, 37(1), 38-57.

Slesnik, N., Vasquez, C. \& Bittinger, J. (2002) Family functioning, substance use and related problem behaviors: Hispanic vs. Anglo runaway youths. Journal of Ethnicity in Substance Abuse, 1(4), 83-101.

Southam-Gerow, M. A., Weisz, J. R., Kendall, P. C. (2003). Youth with anxiety disorders in research and service clinics: Examining client differences and similarities. Journal of Clinical Child and Adolescent Psychology, 32(3), 375385.

Smith, K. M., Taylor, S., Hill, B., \& Zabriskie, R. B. (2004). Family functioning and leisure in single-parent families. Abstracts from the 2004 Leisure Research Symposium. Ashburn, VA: National Recreation and Parks Association. Taylor, S. (2005). Praying, playing and happy families: An examination of the 
relationship between family religiosity, family recreation, and family functioning. Unpublished master’s thesis, Brigham Young University, Provo, UT.

Taylor, S., Zabriskie, R. B., Smith, K. M., \& Hill, B. J. (2004). Family leisure functioning in single-parent families: A preliminary study. Proceedings of the Annual Conference of the National Council on Family Relations, Orlando, FL.

U.S. Bureau of the Census. (1992). Census of the population: General population characteristics, United States: 1990. Washington, DC: U.S. Government Printing Office.

Wallerstein, J., Lewis, J. M., \& Blakeslee, S. (2000). The unexpected legacy of divorce. New York: Hyperion.

Weitoft, G. R., Hjern, A., Haglund, B., Rosen, M. (2003). Mortality, severe morbidity, and injury in children living with single parents in Sweden: A population-based study. Lancet, 361(9354), 289-295.

Wells, M. S., Widmer, M. A., \& McCoy, J. K. (2004). Grubs and grasshoppers: Challenge-based recreation and the collective efficacy of families with at-risk youth. Family Relations, 53(3), 326-333.

White, J. M., \& Klein, D. M. (2002). Family theories: An introduction, Second Edition. Thousand Oaks, CA: Sage.

Zabriskie, R. B. (2000). An examination of family and leisure behavior among families with middle school aged children. Unpublished doctoral dissertation, Indiana University, Bloomington.

Zabriskie, R. B. (2001). The validity and reliability of the Family Leisure Activity Profile 
(FLAP). In M. E. Havitz, \& M. F. Floyd (Eds.), Abstracts of the 2001 Symposium on Leisure Research (p. 66). Ashburn, VA: National Recreation and Park Association.

Zabriskie, R. B., \& Freeman, P. (2004). Contributions of family leisure to family functioning among transracial adoptive families. Adoption Quarterly, 7(3), 49-77.

Zabriskie, R. B., \& McCormick, B. P. (2001). The influences of family leisure patterns on perceptions of family functioning. Family Relations, 50, 281-289.

Zabriskie, R. B., \& McCormick, B. P. (2003). Parent and child perspectives of family leisure involvement and satisfaction with family life. Journal of Leisure Research, 35(2), 163-189. 
Appendix A-1a

Informed Consent 
Consent to be a research subject - Parent

Thank you for participating in our research! Your participation is greatly appreciated. Please complete the following questionnaire. This questionnaire will take approximately 15 minutes to answer. The intent of this study is to examine recreation involvement in families. Results may benefit families through a better understanding of the relationship between family recreation and strong families. There are no known risks for participation in this study. Participation is optional and completely voluntary. You have the right to withdraw at any time without penalty or you may choose to refuse to participate entirely. There will be no reference to your identification at any point in the research. If you have questions regarding this study please contact Dr. Ramon Zabriskie at (801) 422-1667. If you have questions regarding your rights as a participant please contact Dr. Renea Beckstrand, Chair of the Institutional Review Board for Human Subjects at Brigham Young University. (422 SWKT, BYU, Provo, UT 84602; phone [801] 422-3873; email renea_beckstrand@byu.edu) By completing this questionnaire your consent to participate is implied.

Click the "next" button to continue. 
Consent to be a research subject - Youth

This is the YOUTH portion of the survey. It should be completed by a youth ages 11-15.

Family Leisure Activity Profile

The following questions ask about the activities you do with family members. Please refer to the last year or so. These questions ask about groups of activities, so try to answer in terms of the group as opposed to any one specific example. This may require you to "average” over a few different activities. Don't worry about getting it exactly "right." Just give your best estimate.

Symbol Key:

$<=$ less than (e.g. $<1$ hour reads "less than one hour")

$>=$ more than (e.g. $>10$ hours reads "more than ten hours")

Push the "next" button to start the survey. 
Appendix A-1b

Family Leisure Activity Profile 


\section{Family Leisure Activity Profile (FLAP)}

The following questions ask about the activities you do with family members. Please refer to the last year or so. These questions ask about groups of activities, so try to answer in terms of the group as opposed to any one specific example. This may require you to “average” over a few different activities. Don’t worry about getting it exactly "right." Just give your best estimate.

Take a moment to look at the example below. This will give you some instruction on how to fill in your answers.

QUESTION: Do you participate in home-based activities (for example watching TV/videos, listening to music, reading books, singing, etc.) with family members?

First do you do these activities?

$\rightarrow$ YES $\underline{X} \quad \mathrm{NO}$

\begin{tabular}{|l|l|}
\hline \multicolumn{2}{|c|}{ If YES how often? } \\
\hline At least daily & \\
\hline At least weekly & $\mathrm{x}$ \\
\hline At least monthly & \\
\hline At least annually & \\
\hline & Next, how often \\
do you usually
\end{tabular}

do these

activities?

\begin{tabular}{|r|r|r|r|r|r|}
\hline \multicolumn{5}{|c|}{ For about how long per time? (check only one) } \\
\hline$<1$ hour & 1-2 hrs & & 2-3 hours & x \\
\hline 3-4 hours & & 4-5 hours & & 5-6hours & \\
\hline 6-7 hours & & 7-8 hours & & 8-9 hours & \\
\hline 9-10 hours & & $>10$ hours & & $>1$ day & \\
\hline
\end{tabular}

Then, about how long, on average, do you typically do this type of activity each time you do it? 
Last, how satisfied are you with your participation with family members in these activities? Please answer this question EVEN IF YOU DO NOT do these activities with your family.

How satisfied are you with your participation with family members in these activities? (please circle one)

Very

Dissatisfied

1
2

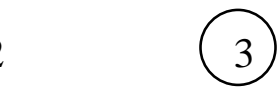

Very

Satisfied

4

5

\section{Symbol Key \\ $<=$ less than (e.g. $<1$ hour reads "less than one hour") \\ $>=$ more than (e.g. $>10$ hours reads " more than ten hours”)}




\section{Do you have dinners, at home, with family members?}

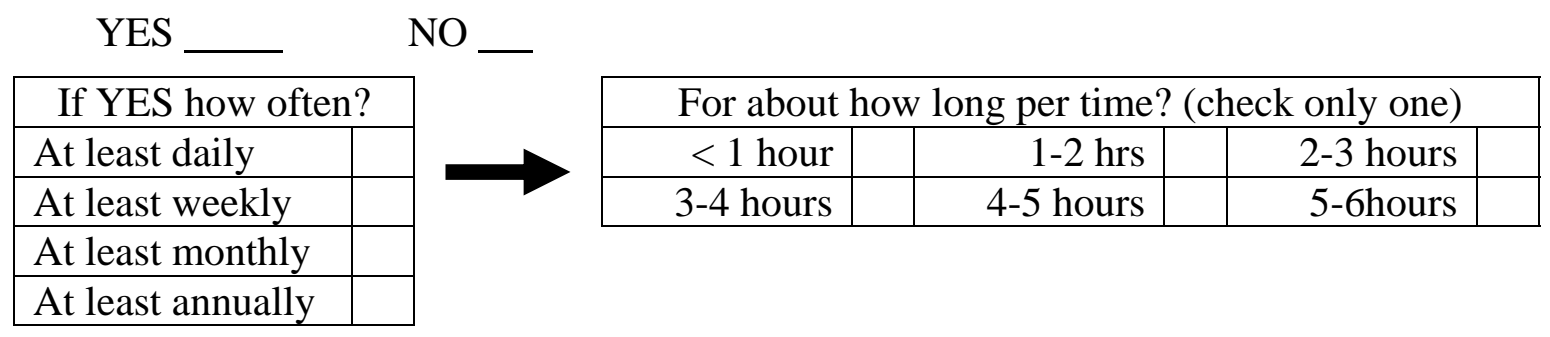

How satisfied are you with your participation or lack of participation, with family members in these activities? (please circle one)

Very

Dissatisfied

1
2

3

4

Very

Satisfied

5

\section{Do you participate in home-based activities (for example watching TV/videos,} listening to music, reading books, singing, etc.) with family members?

\begin{tabular}{|c|c|c|c|c|}
\hline YE & \multirow[t]{2}{*}{$\mathrm{NO}$} & & & \\
\hline If YES how often? & & \multicolumn{3}{|c|}{ For about how long per time? (check only one) } \\
\hline At least daily & & $<1$ hour & $1-2 \mathrm{hrs}$ & 2-3 hours \\
\hline At least weekly & & 3-4 hours & 4-5 hours & 5-6hours \\
\hline At least monthly & & 6-7 hours & 7-8 hours & 8-9 hours \\
\hline At least annually & & 9-10 hours & $>10$ hours & $>1$ day \\
\hline
\end{tabular}

How satisfied are you with your participation with family members in these activities? (please circle one)

Very

Dissatisfied
Very

Satisfied 


\section{Do you participate in games (for example playing cards, board games, video games, darts, billiards, etc.) with family members?}

\begin{tabular}{|c|c|c|c|c|}
\hline YES & NO & & & \\
\hline If YES how often? & & For about & ng per time & only one) \\
\hline At least daily & & $<1$ hour & $1-2 \mathrm{hrs}$ & 2-3 hours \\
\hline At least weekly & & 3-4 hours & 4-5 hours & 5-6hours \\
\hline At least monthly & & 6-7 hours & 7-8 hours & 8-9 hours \\
\hline At least annually & & 9-10 hours & $>10$ hours & $>1$ day \\
\hline
\end{tabular}

How satisfied are you with your participation with family members in these activities? (please circle one)

\author{
Very \\ Dissatisfied
}

1

2

3

4

Very

Satisfied

5

4. Do you participate in crafts, cooking, and/or hobbies (for example drawing, scrap books, baking cookies, sewing, painting, ceramics, etc.) with family members?

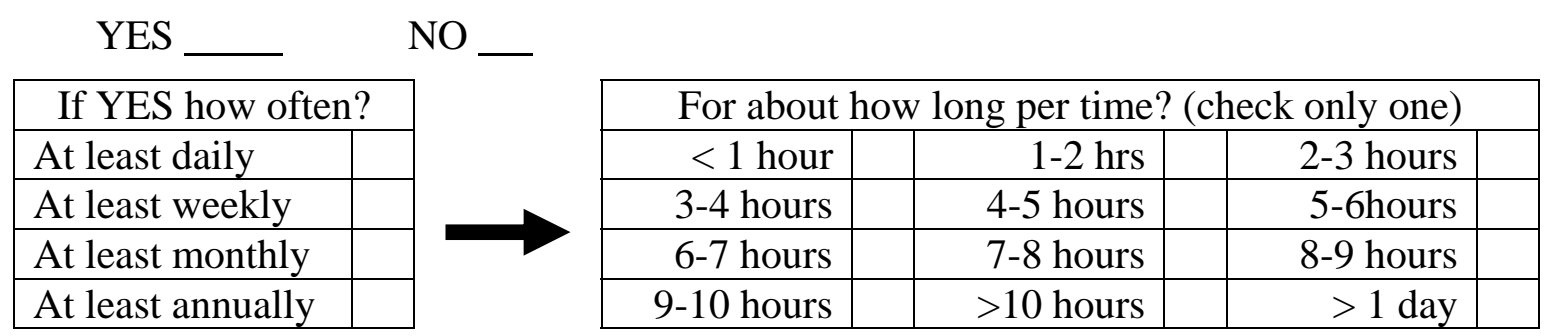

How satisfied are you with your participation with family members in these activities? (please circle one)

Very

Dissatisfied

1
2

3
Very

Satisfied

4 
5. Do you participate in home-based outdoor activities (for example star gazing, gardening, yard work, playing with pets, walks, etc.) with family members?

\begin{tabular}{|c|c|c|c|c|}
\hline YES & \multirow[t]{2}{*}{$\mathrm{NO}$} & & & \\
\hline If YES how often? & & \multicolumn{3}{|c|}{ For about how long per time? (check only one) } \\
\hline At least daily & & $<1$ hour & $1-2 \mathrm{hrs}$ & $2-3$ hours \\
\hline At least weekly & & 3-4 hours & 4-5 hours & 5-6hours \\
\hline At least monthly & & 6-7 hours & $7-8$ hours & 8-9 hours \\
\hline At least annually & & 9-10 hours & $>10$ hours & $>1$ day \\
\hline
\end{tabular}

How satisfied are you with your participation with family members in these activities? (please circle one)
Very
Dissatisfied
Very
Satisfied
1
2
3
4
5

6. Do you participate in home-based sport/games activities (for example playing catch, shooting baskets, frisbee, bike rides, fitness activities, etc.) with family members?

YES NO - -
\begin{tabular}{|l|l|}
\hline If YES how often? \\
\hline At least daily & \\
\hline At least weekly & \\
\hline At least monthly & \\
\hline At least annually & \\
\hline
\end{tabular}

How satisfied are you with your participation with family members in these activities? (please circle one)

Very

Dissatisfied

1
Very

Satisfied

4

5 
7. Do you attend other family members' activities (for example watching or leading their sporting events, musical performances, scouts, etc.)?

YES _ NO N

\begin{tabular}{|l|l|}
\hline \multicolumn{1}{|c|}{ If YES how often? } \\
\hline At least daily & \\
\hline At least weekly & \\
\hline At least monthly & \\
\hline At least annually & \\
\hline
\end{tabular}$\quad$\begin{tabular}{|r|r|r|r|r|r|}
\hline \multicolumn{5}{|c|}{ For about how long per time? (check only one) } \\
\hline 3-4 hours & & 4-5 hours & & 5-6hours & \\
\hline $6-7$ hours & & $7-8$ hours & & 8-9 hours & \\
\hline 9-10 hours & & $>10$ hours & & $>1$ day & \\
\hline
\end{tabular}

How satisfied are you with your participation with family members in these activities? (please circle one)
Very
Dissatisfied
Very
1
2
3
4
Satisfied
5

8. Do you participate in religious/spiritual activities (for example going to church activities, worshipping, scripture reading, Sunday school, etc.) with family members?

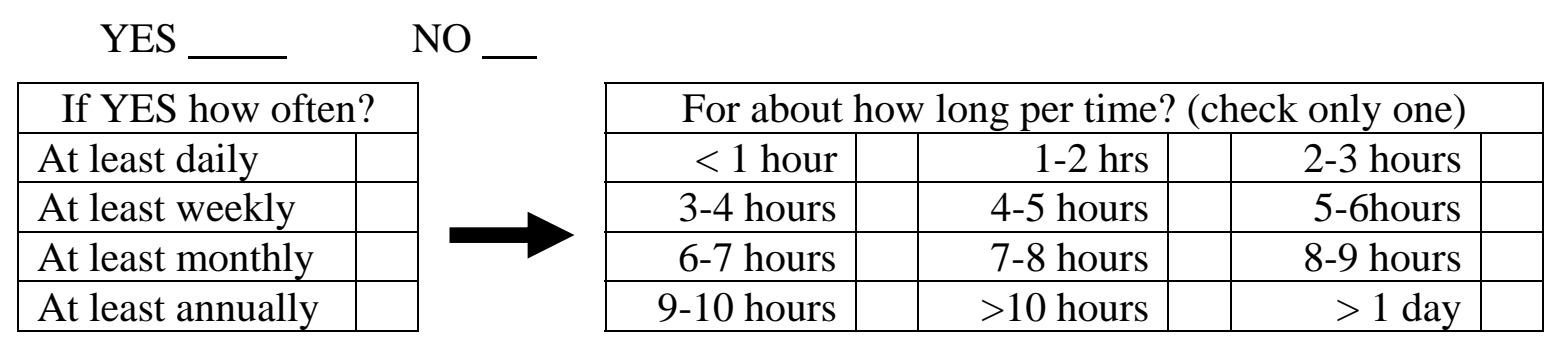

How satisfied are you with your participation with family members in these activities? (please circle one)

Very

Dissatisfied

1
2
Very

Satisfied

4 
9. Do you participate in community-based social activities (for example going to restaurants, parties, shopping, visiting friends/ neighbors, picnics, etc.) with family members?

$$
\text { YES }
$$

$\mathrm{NO}$

\begin{tabular}{|l|l|}
\hline \multicolumn{2}{|c|}{ If YES how often? } \\
\hline At least daily & \\
\hline At least weekly & \\
\hline At least monthly & \\
\hline At least annually & \\
\hline
\end{tabular}

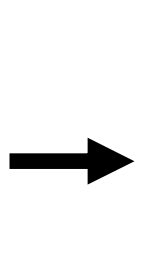

\begin{tabular}{|r|r|r|r|r|}
\hline \multicolumn{5}{|c|}{ For about how long per time? (check only one) } \\
\hline$<1$ hour & 1 - 2 hrs & & 2 -3 hours & \\
\hline 3-4 hours & 4-5 hours & & 5-6hours & \\
\hline 6-7 hours & 7-8 hours & & 8-9 hours & \\
\hline 9-10 hours & $>10$ hours & & $>1$ day & \\
\hline
\end{tabular}

How satisfied are you with your participation with family members in these activities? (please circle one)

Very

Dissatisfied

1
2
3
Very

Satisfied

5

\section{Do you participate in spectator activities (for example going to movies, sporting events, concerts, plays or theatrical performances, etc.) with family} members?

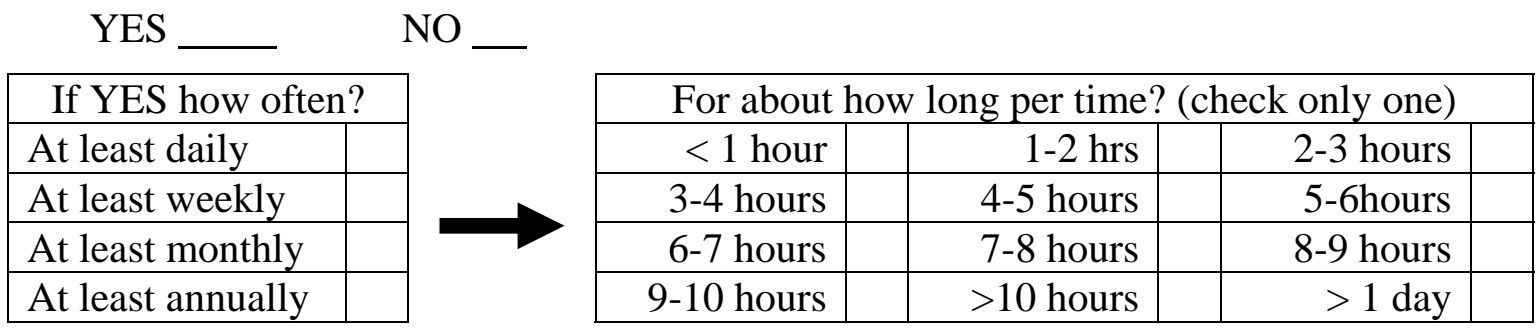

How satisfied are you with your participation with family members in these activities? (please circle one)

Very

Dissatisfied
2
3
Very

Satisfied

4

5 
11. Do you participate in community-based sporting activities (for example bowling, golf, swimming, skating, etc.) with family members?

YES NO -
\begin{tabular}{|l|l|}
\hline If YES how often? \\
\hline At least daily & \\
\hline At least weekly & \\
\hline At least monthly & \\
\hline At least annually & \\
\hline
\end{tabular}
\begin{tabular}{|r|r|r|r|r|r|}
\hline For about how long per time? (check only one) \\
\hline 3-4 hours & & $4-5$ hours & & 5-6hours & \\
\hline 6-7 hours & & $7-8$ hours & & 8-9 hours & \\
\hline 9-10 hours & & $>10$ hours & & $>1$ day & \\
\hline
\end{tabular}

How satisfied are you with your participation with family members in these activities? (please circle one)
Very
Dissatisfied
Very
1
2
3
4
Satisfied

12. Do you participate in community-based special events (for example visiting museums, zoos, theme parks, fairs, etc.) with family members?
YES
NO

\begin{tabular}{|l|l|}
\hline \multicolumn{2}{|c|}{ If YES how often? } \\
\hline At least daily & \\
\hline At least weekly & \\
\hline At least monthly & \\
\hline At least annually & \\
\hline
\end{tabular}

\begin{tabular}{|c|c|c|}
\hline \multicolumn{3}{|c|}{ For about how long per time? (check only one) } \\
\hline$<1$ hour & $1-2$ hrs & $2-3$ hours \\
\hline 3-4 hours & 4-5 hours & 5-6hours \\
\hline 6-7 hours & 7-8 hours & 8-9 hours \\
\hline 9-10 hours & $>10$ hours & \\
\hline 1 day & 8 days & 15 days \\
\hline 2 days & 9 days & 16 days \\
\hline 3 days & 10 days & 17 days \\
\hline 4 days & 11 days & 18 days \\
\hline 5 days & 12 days & 19 days \\
\hline 6 days & 13 days & 20 days \\
\hline One week & Two weeks & $\begin{array}{r}\text { or more } \\
\text { weeks } \\
\end{array}$ \\
\hline
\end{tabular}

How satisfied are you with your participation with family members in these activities? (please circle one)

\section{Very}

Dissatisfied

1
2
3
Very

Satisfied

4
5 
13. Do you participate in outdoor activities (for example camping, hiking, hunting, fishing, etc.) with family members?

YES _ NO

\begin{tabular}{|l|l|}
\hline \multicolumn{2}{|c|}{ If YES how often? } \\
\hline At least daily & \\
\hline At least weekly & \\
\hline At least monthly & \\
\hline At least annually & \\
\hline
\end{tabular}

\begin{tabular}{|r|r|r|r|r|}
\hline \multicolumn{5}{|c|}{ For about how long per time? (check only one) } \\
\hline$<1$ hour & $1-2$ hrs & $2-3$ hours & \\
\hline 3-4 hours & 4-5 hours & 5-6hours & \\
\hline 6-7 hours & $7-8$ hours & 8 -9 hours & \\
\hline 9-10 hours & $>10$ hours & & \\
\hline 1 day & 8 days & 15 days & \\
\hline 2 days & 9 days & 16 days & \\
\hline 3 days & 10 days & 17 days & \\
\hline 4 days & 11 days & 18 days & \\
\hline 5 days & 12 days & 19 days & \\
\hline 6 days & 13 days & 20 days & \\
\hline One week & Two weeks & 3 or more & \\
& & & weeks & \\
\hline
\end{tabular}

How satisfied are you with your participation with family members in these activities? (please circle one)

Very

Dissatisfied

1
Very Satisfied

5 
14. Do you participate in water-based activities (for example water skiing, jet skiing, boating, sailing, canoeing, etc.) with family members?

YES

\begin{tabular}{|l|l|}
\hline \multicolumn{2}{|c|}{ If YES how often? } \\
\hline At least daily & \\
\hline At least weekly & \\
\hline $\begin{array}{l}\text { At least monthly } \\
\text { (during season) }\end{array}$ \\
\hline At least annually \\
\hline
\end{tabular}

\begin{tabular}{|c|c|c|}
\hline \multicolumn{3}{|c|}{ For about how long per time? (check only one) } \\
\hline$<1$ hour & $1-2 \mathrm{hrs}$ & $2-3$ hours \\
\hline 3-4 hours & 4-5 hours & 5-6hours \\
\hline 6-7 hours & 7-8 hours & 8-9 hours \\
\hline 9-10 hours & $>10$ hours & \\
\hline 1 day & 8 days & 15 days \\
\hline 2 days & 9 days & 16 days \\
\hline 3 days & 10 days & 17 days \\
\hline 4 days & 11 days & 18 days \\
\hline 5 days & 12 days & 19 days \\
\hline 6 days & 13 days & 20 days \\
\hline One week & Two weeks & $\begin{array}{r}3 \text { or more } \\
\text { weeks }\end{array}$ \\
\hline
\end{tabular}

How satisfied are you with your participation with family members in these activities? (please circle one)

Very

Dissatisfied

1
2
Very

Satisfied

4 
15. Do you participate in outdoor adventure activities (for example rock climbing, river rafting, off-road vehicles, scuba diving, etc.) with family members?

\begin{tabular}{|c|c|c|c|}
\hline \multicolumn{4}{|l|}{ YES } \\
\hline If YES how often? & \multicolumn{3}{|c|}{ For about how long per time? (check only one) } \\
\hline At least daily & $<1$ hour & $1-2$ hrs & $2-3$ hours \\
\hline At least weekly & 3-4 hours & 4-5 hours & 5-6hours \\
\hline At least monthly & 6-7 hours & 7-8 hours & 8-9 hours \\
\hline At least annually & 9-10 hours & $>10$ hours & \\
\hline & 1 day & 8 days & 15 days \\
\hline & 2 days & 9 days & 16 days \\
\hline & 3 days & 10 days & 17 days \\
\hline & 4 days & 11 days & 18 days \\
\hline & 5 days & 12 days & 19 days \\
\hline & 6 days & 13 days & 20 days \\
\hline & One week & Two weeks & $\begin{array}{r}3 \text { or more } \\
\text { weeks }\end{array}$ \\
\hline
\end{tabular}

How satisfied are you with your participation with family members in these activities? (please circle one)

Very

Dissatisfied

1
2
3
Very

Satisfied

4

5 
16. Do you participate in tourism activities (for example family vacations, traveling, visiting historic sites, visiting state/national parks, etc.) with family members?

YES _ _ NO

\begin{tabular}{|l|l|}
\hline \multicolumn{2}{|c|}{ If YES how often? } \\
\hline At least daily & \\
\hline At least weekly & \\
\hline At least monthly & \\
\hline At least annually & \\
\hline
\end{tabular}

\begin{tabular}{|r|r|r|r|r|}
\hline \multicolumn{5}{|c|}{ For about how long per time? (check only one) } \\
\hline$<1$ hour & $1-2$ hrs & 2 -3 hours & \\
\hline 3-4 hours & $4-5$ hours & 5-6hours & \\
\hline 6-7 hours & $7-8$ hours & $8-9$ hours & \\
\hline 9-10 hours & $>10$ hours & & \\
\hline 1 day & 8 days & 15 days & \\
\hline 2 days & 9 days & 16 days & \\
\hline 3 days & 10 days & 17 days & \\
\hline 4 days & 11 days & 18 days & \\
\hline 5 days & 12 days & 19 days & \\
\hline 6 days & 13 days & 20 days & \\
\hline One week & Two weeks & 3 or more & \\
& & & weeks & \\
\hline
\end{tabular}

How satisfied are you with your participation with family members in these activities? (please circle one)

\section{Very}

Dissatisfied

1
2
Very

Satisfied 
Below are seven statements with which you may agree or disagree. Using the 1-7 scale below, indicate your agreement with each item by circling the appropriate number on the line following that item. Please be open and honest in responding.

$\begin{array}{ccccccc}1 & 2 & 3 & 4 & 5 & 6 & 7 \\ \text { strongly } & \text { disagree } & \text { slightly } & \text { neither agree } & \text { slightly } & \text { agree } & \text { strongly } \\ \text { disagree } & & \text { disagree } & \text { nor disagree } & \text { agree } & & \text { agree }\end{array}$

1. In most ways my family life is close to ideal $\quad \begin{array}{llllllll}1 & 2 & 3 & 4 & 5 & 6 & 7\end{array}$

2. The conditions of my family life are excellent. $\begin{array}{lllllllll}1 & 2 & 3 & 4 & 5 & 6 & 7\end{array}$

3. I am satisfied with my family life. $\quad \begin{array}{llllllll}1 & 2 & 3 & 4 & 5 & 6 & 7\end{array}$

4. So far I have gotten the important things I want $\quad \begin{array}{lllllllll}1 & 2 & 3 & 4 & 5 & 6 & 7\end{array}$ in my family life

5. If I could live my family life over, I would $\quad \begin{array}{lllllllll}1 & 2 & 3 & 4 & 5 & 6 & 7\end{array}$ change almost nothing

6. Family leisure activities are an important part $\quad \begin{array}{lllllllll}1 & 2 & 3 & 4 & 5 & 6 & 7\end{array}$ of our family life.

$\begin{array}{lllllllllll}\text { 7. Family leisure adds to the quality of my family } & 1 & 2 & 3 & 4 & 5 & 6 & 7\end{array}$ life.

(Zabriskie, 2000) 
Appendix A-1c

Family Adaptability and Cohesion Scale II 


\section{Family Adaptability and Cohesion Scales}

\section{(FACES II)}

Please answer the following questions in reference to your family currently. Please be as open and honest as possible. All responses are strictly confidential.

Use the following scale:

1

Almost never Once in awhile
3

Sometimes
4 Frequently
5

Almost always

\section{Describe your family:}

1. Family members are supportive of each other during difficult times.

2. In our family, it is easy for everyone to express his/her opinion.

3. It is easier to discuss problems with people outside the family than with other family members.

4. Each family member has input regarding major family decisions.

5. Our family gathers together in the same room.

6. Children have a say in their discipline.

7. Our family does things together.

8. Family members discuss problems and feel good about the solutions.

9. In our family, everyone goes his/her own way.

10. We shift household responsibilities from person to person.

11. Family members know each other's close friends.

12. It is hard to know what the rules are in our family.

13. Family members consult other family members on personal decisions.

14. Family members say what they want.

15. We have difficulty thinking of things to do as a family.

16. In solving problems, the children's suggestions are followed.

17. Family members feel very close to each other.

18. Discipline is fair in our family.

19. Family members feel closer to people outside the family than to other family members.

20. Our family tries new ways of dealing with problems.

21. Family members go along with what the family decides to do.

22. In our family, everyone shares responsibilities.

23. Family members like to spend their free time with each other.

24. It is difficult to get a rule changed in our family.

25. Family members avoid each other at home.

26. When problems arise, we compromise.

27. We approve of each other's friends.

28. Family members are afraid to say what is on their minds.

29. Family members pair up rather than do things as a total family.

30. Family members share interests and hobbies with each other.

(Olson, 1986) 
Appendix A-1d

Demographic Questions 


\section{Demographic Questions (Dual-Parent)}

The following section asks some general questions about you and your family.

Are you currently a single-parent?

C Yes

C No

How long have you been a single-parent?

What is your single-parent status?

C Divorced

C Separated

C Widowed

C Never Married

C Other

Are you the custodial parent of the responding youth?
C Yes
C No

What is the percent of time the child/children spend with the non-custodial parent? (Click here to choose) - $\quad{ }_{10} \%, 20 \%, 30 \%, 40 \%, 50 \%, 60 \%, 70 \%, 80 \%, 90 \%, 100 \%$

What is your age?

Gender

C Male

C Female

Q.

Please indicate the total number of immediate family members (parent[s] and child[ren]) 
Family Composition - Please enter the following information about your family*:

\begin{tabular}{|l|l|l|l|l|l|l|l|}
\hline & \multicolumn{2}{|c|}{ Age } & \multicolumn{2}{c|}{ Gender } & \multicolumn{3}{c|}{ What is your relationship to child? (skip } \\
spouse)
\end{tabular}

*Only fill out what applies to your family. Not all answer fields required.

Q.

Have you ever been divorced?

$$
\text { Yes }
$$

No 
What is your ethnicity?

C Asian

C Black, non-hispanic

C Hispanic

C Native American

C Pacific Islander

C White, non-hispanic

State currently living in:

(Click here to choose)

Please indicate the estimated annual income for your family.

C Less than $\$ 10,000$

C 10,000-19,999

C 20,000-29,999

C 30,000-39,999

C 40,000-49,999

C 50,000-59,999

C 60,000-69,999

C 70,000-79,999

C 80,000-99,999

C 100,000-124,999

C 125,000-150,000

E Over $\$ 150,000$

Population of your place of residency:

C Urban/Suburban $(>50,000)$

C Rural $(<50,000)$ 
Demographic Questions (Youth of Dual-Parent)

What is your gender?

C Male

C Female

What is your age?

What is your ethnicity?

C Asian

C Black, non-Hispanic

C Hispanic

C Native American

C Pacific Islander

C White, non-Hispanic 


\section{Demographic Questions (Single-Parent)}

The following section asks some general questions about you and your family.

What is your age?

Gender

C Male

C Female

What is your ethnicity?
C Asian
C Black, non-hispanic
C Hispanic
C Native American
C Pacific Islander
C White, non-hispanic

Marital status - Answer yes to those that apply to you currently*:
Answer yes or no to Please indicate how long for each item each yes answer

\begin{tabular}{lcc} 
& \multicolumn{2}{c}{ each item } \\
Single — never married & Yes & No \\
Separated & $\mathbf{C}$ & $\mathbf{C}$ \\
Divorced & $\mathbf{C}$ & $\mathbf{C}$ \\
Widowed & $\mathbf{C}$ & $\mathbf{C}$ \\
Unmarried - living with partner & $\mathbf{C}$ & $\mathbf{C}$ \\
Married & $\mathbf{C}$ & $\mathbf{C}$
\end{tabular}

*Not all answers are required.

State currently living in:

(Click here to choose) 
Please indicate the estimated annual income for your family.

C Less than $\$ 10,000$

C 10,000-19,999

C 20,000-29,999

C 30,000-39,999

C 40,000-49,999

C 50,000-59,999

C 60,000-69,999

C 70,000-79,999

C 80,000-99,999

C 100,000-124,999

C $125,000-150,000$

C Over $\$ 150,000$

Please indicate the total number of immediate family members(parent[s] and child[ren])

Family Composition — Please enter the following information about your family*:

\begin{tabular}{|l|l|l|l|l|l|l|l|}
\hline & \multicolumn{2}{|c|}{ Age } & \multicolumn{2}{|c|}{ Gender } & \multicolumn{3}{c|}{ What is your relationship to child? (skip } \\
spouse)
\end{tabular}




\begin{tabular}{|l|l|l|l|l|l|l|l|}
\hline & \multirow{2}{*}{ Age } & \multicolumn{2}{|c|}{ Gender } & \multicolumn{3}{c|}{ What is your relationship to child? (skip } \\
spouse)
\end{tabular}

*Only fill out what applies to your family. Not all answer fields required.

Have you ever been divorced?

$\begin{array}{ll}\boldsymbol{C} & \text { Yes } \\ \text { C } & \text { No }\end{array}$

Population of your place of residency:

C Urban/Suburban (>50,000)

C Rural $(<50,000)$ 


\section{Demographic Questions (Youth of Single-Parent)}

What is your gender?

C Male

C Female

What is your age?

What is your ethnicity?

C Asian

C Black, non-hispanic

C Hispanic

C Native American

C Pacific Islander

C White, non-hispanic 